OPEN ACCESS

Edited by:

Aldo Corsetti,

Università di Teramo, Italy

Reviewed by:

Vivek K. Bajpai,

Dongguk University Seoul,

South Korea

Amit Kumar Mandal,

Raiganj University, India

${ }^{*}$ Correspondence:

Muhammad Imran

m.imran@comsats.edu.pk

Specialty section:

This article was submitted to

Food Microbiology,

a section of the journal

Frontiers in Microbiology

Received: 12 August 2017 Accepted: 26 December 2017

Published: 15 January 2018

Citation:

Niaz T, Shabbir S, Noor T, Abbasi $R$,

Raza ZA and Imran M (2018)

Polyelectrolyte Multicomponent Colloidosomes Loaded with Nisin Z

for Enhanced Antimicrobial Activity

against Foodborne Resistant

Pathogens. Front. Microbiol. 8:2700.

doi: 10.3389/fmicb.2017.02700

\section{Polyelectrolyte Multicomponent Colloidosomes Loaded with Nisin Z for Enhanced Antimicrobial Activity against Foodborne Resistant Pathogens}

\author{
Taskeen Niaz ${ }^{1}$, Saima Shabbir ${ }^{2}$, Tayyaba Noor ${ }^{3}$, Rashda Abbasi ${ }^{4}$, Zulfiqar A. Raza ${ }^{5}$ and \\ Muhammad Imran ${ }^{\text {t* }}$ \\ ${ }^{1}$ Department of Biosciences, COMSATS Institute of Information Technology, Islamabad, Pakistan, ${ }^{2}$ Department of Materials \\ Science and Engineering, Institute of Space Technology, Islamabad, Pakistan, ${ }^{3}$ School of Chemical and Materials \\ Engineering, National University of Sciences and Technology, Islamabad, Pakistan, ${ }^{4}$ Cancer Research, Institute of Biomedical \\ and Genetic Engineering, Islamabad, Pakistan, ${ }^{5}$ Department of Applied Sciences, National Textile University, Faisalabad, \\ Pakistan
}

Food grade micro- or nano-carrier systems (NCS) are being developed to improve the controlled release of antimicrobial agents. To augment the stability of liposomal NCS and to overcome the limitations associated with the use of free bacteriocin (nisin) in the food system, multi-component colloidosomes (MCCS) were developed by electrostatic interactions between anionic alginate and cationic chitosan (multilayer) around phospholipids based liposomes (core). Zeta-sizer results revealed the average diameter of $145 \pm 2 \mathrm{~nm}, 596 \pm 3 \mathrm{~nm}$, and $643 \pm 5 \mathrm{~nm}$ for nano-liposome (NL), chitosomes (chitosan coated NL) and MCCS, respectively. Zeta potential values of NCS varied from $-4.37 \pm 0.16 \mathrm{mV}$ to $33.3 \pm 6 \mathrm{mV}$, thus both chitosomes (CS) and MCCS were positively charged. Microstructure analysis by scanning electron microscope (SEM) revealed relatively higher size of MCCS with smooth and round morphology. TGA and DSC based experiments revealed that MCCS were thermally more stable than uncoated liposomes. Encapsulation efficiency of nisin in MCCS was observed to be $82.9 \pm 4.1 \%$, which was significantly higher than $\mathrm{NL}(56.5 \pm 2.5 \%)$. FTIR analyses confirmed the cross-linking between sodium alginate and chitosan layer. Both qualitative (growth kinetics) and quantitative (colony forming unit) antimicrobial assays revealed that nisin loaded MCCS have superior potential to control resistant foodborne pathogens including Staphylococcus aureus, Listeria monocytogenes, and Enterococcus faecalis, (5.8, 5.4, and 6.1 Log CFUmL ${ }^{-1}$ reduction, respectively) as compared to free nisin, loaded NL or CS. Controlled release kinetics data fitted with Korsmeyer-Peppas model suggested that nisin release from MCCS followed Fickian diffusion. Cytotoxic studies on human blood cells and HepG2 cell lines revealed hemocompatibility and non-toxicity of 
MCCS. Thus, due to enhanced controlled release, stability and biocompatibility; these multi-component colloidosomes can be useful for incorporating antimicrobial agents into functional foods, beverages and pharmaceutical products to combat pathogenic and spoilage bacteria.

Keywords: bacteriocin, chitosan, chitosomes, food-grade delivery system, MDR pathogens, nano-liposome, Listeria monocytogenes

\section{INTRODUCTION}

Food spoilage caused by pathogenic microorganisms during food storage and distribution has serious impact on food quality, shelflife and food loss (Lopes and Brandelli, 2017). Antimicrobial polypeptides such as nisin are purposefully added in the food systems to control the microbial growth. Nisin, only bacteriocin approved by Food and Drug Authority (Generally Recognized as Safe) and European Union (E234), is known to exert inhibitory effect toward Gram-positive foodborne pathogens e.g., Listeria monocytogenes, Staphylococcus aureus, and Enterococcus faecalis. Directly added bacteriocin to food products may face many challenges e.g., loss of antimicrobial activity, limited stability against chemical or physical degradation, interactions with different food components, its degradation and electrostatic repulsion, uncontrolled release and possible adverse effects on physical qualities of food structure (Fu et al., 2016). One approach to address these problems is the use of food grade nano-carrier systems to improve the stability, bioavailability and activity of antimicrobial agents (Khan and Oh, 2016).

Liposomes are attractive nano-delivery systems that provide number of benefits including large scale production, enhanced stability of encapsulated agents against enzymatic and chemical degradation during food processing. Liposomes have been widely used in food industries because of their biocompatibility, biodegradability, non-toxicity and small size (Imran et al., 2015; Emami et al., 2016; Alavi et al., 2017). However, quick oxidation during storage and lack of stability of liposomal membrane, which results in burst release of active agent, are major obstacles for liposomes' application in the food industry (Liu et al., 2016). In this context, surface modification of liposomes has been investigated to enhance their stability and functionality (Nguyen et al., 2016). For example, coating liposomes with biopolymer can improve its physico-chemical stability, increase drug pay load and enhance its in-vitro digestibility in biologically relevant media (Liu et al., 2017).

Previous studies have revealed that decoration of liposomal surface with biomacromolecules is an effective way to reduce the damage of lipid membrane and associated leakage of encapsulated compounds (Caddeo et al., 2016; Tan et al., 2016; Adamczak et al., 2017; Peng et al., 2017). Chitosan (CTS) is a carbohydrate based poly-cationic linear polymer consisting of (1-4) linkages between D-glucosamine and N-acetyl-Dglucosamine units, and it has demonstrated high biodegradability and biocompatibility (Niaz et al., 2016). Due to the presence of amino groups, chitosan acts as a cationic polymer and makes electrolytic complexes with the oppositely charged molecules (Paques et al., 2014; Li et al., 2016). Liposomes coated with CTS can be prepared through ionic interaction between liposomes and an oppositely charged chitosan. A recent study has highlighted the potential use of CTS as a stability-enhancing agent and bioadhesive material by coating on the liposomal surface (Pistone et al., 2017). However, one of the major limitation of CTS as a coating agent on phospholipids is its easy dissolution in low $\mathrm{pH}$, which results in subsequent release and denaturation of encapsulated agent (Raval et al., 2017).

Sodium alginate (ALG), a water-soluble anionic polymer, is used extensively as a thickener, emulsifier, and stabilizer in the food and pharmaceutical industries (Draget et al., 2016; Tavernier et al., 2016; Khalil et al., 2017). Though ALG can be layered on the external membrane of liposomes for stability purposes, its dissolution in high-pH conditions could result in loss of its stabilizing effect on liposomes and release of entrapped contents (Manatunga et al., 2017). Thus, polyelectrolyte complexation of both CTS and ALG can display improved dissolution of CTS and ALG in different $\mathrm{pH}$ ranges of the food system, as reported previously for inuline (Gandomi et al., 2016).

Thus, the aim of the present study was to fabricate, characterize and evaluate nisin loaded polyelectrolyte multicomponent colloidosomes (MCCS) with layer by layer (LbL) self-assembly of CTS and alginate on nano-liposomes. Chitosan was self-assembled on the surface of cationic nanoliposomes prepared by ultrasonication process, and negatively charged alginate was then deposited on the outer layer of cationic chitosomes (CS). Chitosan-alginate stabilized delivery systems were then characterized by using scanning electron microscopy (SEM), Fourier transform infrared spectroscopy (FTIR), thermal gravimetric analysis (TGA) and differential scanning calorimetry (DSC). Bacteriocin loaded MCCS were also evaluated for their antimicrobial potential against milkborne resistant pathogens e.g., Listeria monocytogenes, Staphylococcus aureus and Enterococcus faecalis. Furthermore, in vitro nisin release kinetics from these formulations were also studied at different $\mathrm{pH}$ and temperatures to assess the sustained release of active agent.

\section{MATERIALS AND METHODS}

\section{Materials}

Sodium alginate [molecular formula: $\left(\mathrm{C}_{6} \mathrm{H}_{7} \mathrm{NaO}_{6}\right)_{\mathrm{n}}$, molecular weight: $176.10 \mathrm{~g} / \mathrm{mol}$ ] was purchased from VWR international. Calcium chloride $\left(\mathrm{CaCl}_{2}\right)$ was purchased from SERVA electrophoresis $\mathrm{GmbH}$. Chitosan (medium molecular weight) $85 \%$ degree of deacetylation, acetic acid (glacial, $\geq 99.85 \%$ ), sodium dodecyl sulfate (SDS) and galactose were purchased from Sigma-Aldrich USA. Growth medium e.g., Muller Hinton, 
Brain heart infusion and Nutrient agar for strains' growth and preservation were also purchased from Sigma-Aldrich. RapID ONE System kits for bacterial identification were procured from Thermo Fisher Scientific. Nisin Z (90\% pure) was purchased from Honghao Chemical Co. Shanghai, China. Purified soy lecithin with $\geqslant 94 \%$ phosphatidylcholine, was provided by Lipoid (Ludwigshafen, Germany). Sodium pyruvate, glutamine, hepes, penicillin/streptomycin and Dulbecco's Modified Eagle Medium (DMEM) for hepG2 cell lines were purchased from Invitrogen.

\section{Isolation, Identification, and Resistance Profiling of Milkborne Pathogens}

Gram-positive foodborne pathogens e.g., Listeria monocytogenes, Staphylococcus aureus, and Enterococcus faecalis were collected from different milk industries in Pakistan. Samples were serially diluted and spread on different differential growth media to isolate desired pathogenic strains, and then morphologically selected colonies were individually purified and subjected for identification. All isolates were examined for biochemical properties using RapID ONE System kits (Thermo Fisher Scientific). Multi drug resistant (MDR) profiles of the identified strains were carried out by disc diffusion method (Benmansour et al., 2016).

\section{Quantification of Nisin by Nano-Photometer}

Stock solution of nisin $(1 \mathrm{mg} / \mathrm{mL})$ was prepared by dissolving $0.01 \mathrm{~g}$ of nisin powder in $10 \mathrm{~mL}$ of distilled water. Working solutions were made by various serial dilutions from stock solution. Wavelength selected after wave scan was $291 \mathrm{~nm}$ by using Multiskan ${ }^{\mathrm{TM}}$ GO Microplate Spectrophotometer. Optical density (OD) values were recorded for each dilution in triplicate and then respective standard curve was prepared by Bradford assay.

\section{Minimum Inhibitory Concentration (MIC) of Nisin Z}

MIC of bacteriocin was obtained by spot on lawn method. Nisin solutions at different concentrations $(1,000-5 \mu \mathrm{g} / \mathrm{mL})$ were made by serially diluting the stock solution. Freshly cultured colony of each pathogen was spread on nutrient agar plate separately. Afterwards, $10 \mu \mathrm{L}$ of sample was taken from each nisin dilution and spotted it on freshly spread bacterial culture. MIC was the lowest concentration of bacteriocin resulting in inhibition of visible growth after $24 \mathrm{~h}$ (Balay et al., 2017).

\section{Optimization of Multicomponent Colloidosomes (MCCS)}

Solution A was prepared by adding soy lecithin $(10 \mathrm{mg} / \mathrm{mL})$ in distilled water and stirred for $4 \mathrm{~h}(1,200 \mathrm{rpm})$. After complete dissolution of lecithin dispersion, it was sonicated for $15 \mathrm{~min}$ by ultra-sonicater. Solution B was prepared by dissolving CTS $(0.6 \% \mathrm{w} / \mathrm{v})$ in $1 \%(\mathrm{v} / \mathrm{v})$ glacial acetic acid aqueous solution, and solution $\mathrm{C}$ was prepared by adding $0.5 \% \mathrm{w} / \mathrm{v}$ sodium alginate in $\mathrm{dH}_{2} \mathrm{O}$. Afterwards, $\mathrm{pH}$ of both solution $\mathrm{B}$ and $\mathrm{C}$ were adjusted to 5 followed by overnight stirring at $1,200 \mathrm{rpm}$ and filtration. Chitosan coated nano-liposomes i.e., chitosomes (CS) were prepared by adding equal volume of solution A dropwise into solution $B(1: 1, v / v)$, and then incubated for $1 \mathrm{~h}$ under gentle stirring. Dispersion was sonicated for $15 \mathrm{~min}$ after incubation. Multicomponent nanoliposomes (LPs-CTS-ALG) were prepared by ionotropic pre-gelation methods. For the fabrication of MCCS equal volume of chitosomes were added into the solution $\mathrm{C}(1: 1$, $\mathrm{v} / \mathrm{v})$ and incubated for $1 \mathrm{~h}$ under constant magnetic stirring. Subsequently, equal volume of calcium chloride solution $(18 \mathrm{mM}$ of $\mathrm{CaCl}_{2}$ ) was added in the above solution. Afterwards, the solution was subjected to sonication for $15 \mathrm{~min}$ to obtain multicomponent colloidosomes (MCCS). Both CS and MCCS were centrifuge at $15,000 \mathrm{~g}$ for $30 \mathrm{~min}$ for further characterization of EE. Nisin loaded carrier systems were fabricated accordingly by dissolving nisin in distilled water before soy lecithin addition in solution A.

\section{Size and Zeta Potential of Void and Nisin-Loaded Carrier Systems}

Mean particle size and zeta potential of the blank and bacteriocin loaded MCCS were calculated by using Zeta-sizer Nano-ZS (Malvern, UK). This instrument works on the principle of dynamic light scattering (DLS). It comprises of $4 \mathrm{~mW} \mathrm{He} / \mathrm{Ne}$ laser, photo multiplier, measurement cell and correlator. Briefly, $3 \mathrm{~mL}$ suspension of nanoliposomes (LPs), CTS coated liposomes and MCCS (LPs-CTS-ALG) were diluted with deionized water and average size distributions and zeta potential of particles were measured at $25^{\circ} \mathrm{C}$ with refractive index of 1.33 .

\section{Physical Stability Analysis of Nano-Formulations with DLS}

DLS technique was used to determine the average size, zeta potential (ZP) and polydispersity index (PDI), which are considered as stability indicators for nano-carrier systems. PDI illustrates the homogeneity of the colloidal dispersion and zeta potential determines the net charge on NCS, both of these parameters help to predict the stability of colloidosomes during storage period (Koirala et al., 2016). Therefore, to determine the stability of MCCS, mean particle size, polydispersity index (PDI) and zeta potential (ZP) were measured for 3 weeks at room temperature $\left(25^{\circ} \mathrm{C}\right)$. All the measurements were taken in triplicate.

\section{Encapsulation Efficiency of Nisin}

MCCS dispersion was centrifuge at $15,000 \mathrm{rpm}$ and un-encapsulated (free) nisin in the supernatant was measured by checking its optical density (OD) value at $291 \mathrm{~nm}$ with nano-spectrophotometer (Implen). By comparing OD values of nisin with the standard curve, specific concentration of the encapsulated bacteriocin was calculated. The total amount of nisin was referred to its initial concentration added into the formulation during NCS fabrication. Encapsulation efficiency (EE \%) of bacteriocin was calculated using the Equation (1).

$$
\begin{aligned}
\mathrm{EE} \%= & {[\text { Encapsulated drug }(\text { Total drug }- \text { Free drug })] } \\
& /[\text { Total drug }] \times 100
\end{aligned}
$$




\section{Scanning Electron Microscopy (SEM)}

To investigate the morphology of void and nisin loaded multicomponent NCS, SEM was performed by using Field Emission Scanning Electron Microscope (FE-SEM) (Tescan, USA). About 2-5 $\mu \mathrm{L}$ of NCS suspension was spread on a glass slide $(1 \times 1 \mathrm{~cm})$ and dried at room temperature. Air-dried samples were sputter coated with carbon. Samples were analyzed for shape and size using an electron acceleration voltage of $5-10 \mathrm{KeV}$ (Sadiq et al., 2016).

\section{Thermal Analysis of Biopolymer, Active Agent and Nano-Antimicrobials}

\section{Thermogravimetric Analysis (TGA)}

TGA analysis was performed on Shimadzu TGA-50, Japan. Temperature scans of the samples were carried out under dynamic nitrogen atmosphere with heating rate of $10^{\circ} \mathrm{C} / \mathrm{min}$. Minimum $10 \mathrm{mg}$ sample was placed in alumina crucible pan and subjected to TGA analysis with temperature range from 0 to $600^{\circ} \mathrm{C}$ (Sood et al., 2017).

\section{Differential Scanning Calorimetry (DSC)}

DSC studies were performed using a Shimadzu DSC-50 equipped with a Mettler Toledo DSC 1 Stare System. Aliquots of about $10 \mathrm{mg}$ of each sample were placed in an aluminum pan before performing DSC measurements. Then, each calorimetric pan was sealed and submitted to DSC analysis for heating range from 0 to $300^{\circ} \mathrm{C}$, at the rate of $2^{\circ} \mathrm{C} / \mathrm{min}$, and $10^{\circ} \mathrm{C} / \mathrm{min}$ under a nitrogen flow of $20 \mathrm{~cm}^{3} / \mathrm{min}$. Reproducibility was checked by analyzing the samples in triplicate.

\section{Fourier Transformed Infrared Spectroscopy (FTIR)}

FTIR based spectroscopic investigation was performed using a PerkinElmer 100 FTIR spectrometer (PerkinElmer, Italy). FTIR spectra of powdered nisin and polymer were recorded with $\mathrm{KBr}$ disc method as reported earlier (Niaz et al., 2016) with few modifications. Powder/dried samples were mixed with an appropriate amount of $\mathrm{KBr}$ to obtain a final concentration (1\% $\mathrm{w} / \mathrm{w}$ ) of samples, whereas liquid nano-formulations were directly analyzed on FTIR spectrometer. FTIR transmission spectra of empty multicomponent NCS and nisin loaded NCS were recorded from 500 to $4,000 \mathrm{~cm}^{-1}$ with a resolution of $1 \mathrm{~cm}^{-1}$.

\section{Antimicrobial Potential of Nano-Antimicrobials Antimicrobial Potential of Different Nano-Active Formulations on Inoculated Agar Media}

To find out the antibacterial activity of MCCS, $10 \mathrm{uL}$ of nano-formulation was placed on nutrient agar medium inoculated with Listeria monocytogenes, Staphylococcus aureus, and Enterococcus faecalis separately on individual Petri dish. Plates were refrigerated at $4^{\circ} \mathrm{C}$ for $2 \mathrm{~h}$ to allow the diffusion of bacteriocin loaded NCS in the agar medium without microbial growth and then incubated at $37^{\circ} \mathrm{C}$.

\section{Growth Kinetics of Foodborne Pathogens Exposed to Nano-Antimicrobials}

The growth kinetics of foodborn pathogenic strains were tested by exposing them to nano-antimicrobials by using a modified protocol reported earlier (Sadiq et al., 2016). Optical density value of inoculated broth containing either free or encapsulated bactericidal agent were recorded at $595 \mathrm{~nm}$ in 96 well plate by using micro-plate absorbance reader (Bio-Rad iMark).

\section{Quantitative Analysis of Nano-Antimicrobials' Potential: Colony Forming Unit (CFUmL ${ }^{-1}$ )}

To determine microbial viability after exposure with nanoantimicrobials, CFU analyses were performed by counting the number of colonies on agar plate as described previously (Jamil et al., 2016b). Briefly colony forming unit (CFU) measurements were performed by taking $100 \mu \mathrm{L}$ of sample from each tube (inoculated with pathogens and with different nano-formulations e.g., NL, CS and MCCS) and serially diluted up to $10^{8}$ dilution factors. After specific intervals, $20 \mu \mathrm{L}$ from each diluent was spread on LB agar with a sterile cotton swab and Petri plates were incubated for $24 \mathrm{~h}$. Individual bacterial colonies on the agar plate were counted manually.

\section{In Vitro Controlled Release Kinetics of Bacteriocin}

In vitro controlled release of nisin from polyelectrolyte multicomponent NCS was performed as described previously by Niaz et al. (2016), with slight modifications. Nisin loaded NCS were incubated in $0.1 \mathrm{M}$ phosphate buffer saline (PBS) with $\mathrm{pH} 7$ and $\mathrm{pH}$ 4. Controlled release profiles were observed at two different temperatures i.e., 4 and $37^{\circ} \mathrm{C}$, respectively. After regular intervals, $2 \mathrm{~mL}$ suspension (nisin loaded MCCS in PBS) was withdrawn, centrifuged and analyzed for free nisin by nanophotometer. To determine the release kinetics of nisin from NCS Korsmeyer-Peppas and Higuchi mathematical models were applied.

Higuchi model (Equation 2), was used to determine the release of drug by diffusion, which plots percentage drug release against the square root of time. Where $\mathrm{K}_{\mathrm{H}}$ is Higuchi dissolution constant and $\mathrm{Q}$ is the amount of active agent release in time " $\mathrm{t}$ " (Jain and Jain, 2016).

$$
\mathrm{Q}=\mathrm{K}_{\mathrm{H}} \mathrm{t}^{1 / 2}
$$

Moreover, Korsmeyer-Peppas model (Equation 3) was applied to assess Fickian as well as non-Fickian, anomalous, case II and super case II transport of encapsulated antimicrobial from MCCS at different $\mathrm{pH}$ and temperatures. Initial $60 \%$ drug release data was fitted with this model (Hervault et al., 2016).

$$
\mathrm{Mt} / \mathrm{M}_{\infty}=\mathrm{K}_{\mathrm{kp}} \mathrm{t}^{\mathrm{n}}
$$

Where Mt is the mass of bacteriocin (nisin) released at time t, $\mathrm{M} \infty$ represents the total mass of nisin to be released and $\mathrm{k}$ is a constant which represents the structural characteristics of the nano-carrier systems. The exponent $\mathrm{n}$ indicates the type of release and its value changes with the change in release mechanism of diffusion e.g., nisin diffusion will be Fickian when $n=0.43$. For NCS having high polydispersity, value of $\mathrm{n}$ less than 0.43 could 
also be possible and considered as Fickian diffusion (Koirala et al., 2016). The values of $\mathrm{n}$ between 0.5 and 1.0 are indicative of anomalous, Case II transport, super-case II non-Fickian diffusion (de Oliveira Pedro et al., 2018).

\section{In Vitro Hemolysis Analysis}

In vitro hemolysis assay of NCS was performed as described previously (Jamil et al., 2016a). Briefly human whole blood sample was collected in $\mathrm{Li}$-heparin as anti-coagulant vacutainer. Blood sample was incubated with $1 \%$ of nano-antimicrobials' solution at $37^{\circ} \mathrm{C}$ for $45 \mathrm{~min}$. Unexposed samples were taken as negative control, whereas sodium dodecyl sulfate (1\% SDS) solution was added as positive control in the blood sample. After incubation, samples were centrifuged at $14,000 \mathrm{rpm}$ for $5 \mathrm{~min}$. After centrifugation, supernatant was collected from each samples and OD was measured at $540 \mathrm{~nm}$ by Multiskan ${ }^{\mathrm{TM}}$ GO microplate spectrophotometer. Percentage hemolysis was calculated relative to the untreated control. All assay values were observed in duplicate.

\section{Cytotoxicity Assessment on Human HepG2 Cell Line} HepG2 cells were cultured in DMEM with $10 \%$ (v/v) heatinactivated fetal bovine serum (FBS), Na-pyruvate ( $1 \mathrm{mM}$ ), L-glutamine $(2 \mathrm{mM})$, galactose $(10 \mathrm{mM})$, hepes $(5 \mathrm{mM})$, and penicillin/streptomycin $(100 \mathrm{iU} / \mathrm{mL})$. The cells were kept at $37^{\circ} \mathrm{C}$ under humidified condition with $5 \%$ carbon dioxide $\left(\mathrm{CO}_{2}\right)$ and 95\% air.

The sulforhodamine B (SRB) cell viability assay was used to detect the cytotoxicity of the nanocarrier systems against HepG2 (ATCC HB-8065TM) cell lines as described previously (Dai et al., 2017). Briefly, HepG2 cells were harvested overnight in 96-wells plates $(15,000$ cells/well), Next day, cells were exposed to nanoantimicrobials and incubated for $24 \mathrm{~h}$ at $37^{\circ} \mathrm{C}$ with $5 \% \mathrm{CO}_{2}$. After incubation, the monolayers of cells were fixed with $10 \%(\mathrm{w} / \mathrm{v})$ trichloro acetic acid (TCA) and kept at $4^{\circ} \mathrm{C}$ for at least $2 \mathrm{~h}$.

The samples were carefully washed with deionized water, air dried and stained for $30 \mathrm{~min}$ with $0.4 \%$ SRB solution. Samples were washed with $1 \%$ acetic acid and dried overnight. Photographs of the dried samples were taken by Olympus IMT-2 inverted microscope equipped with digital camera. The incorporated dye was solubilized in $0.01 \mathrm{M}$ Tris solution and $\mathrm{OD}$ at $565 \mathrm{~nm}$ was measured on spectrophotometer (de Oliveira Pedro et al., 2018). Unexposed cells were considered as control and relative cell viability was calculated as a percentage in triplicate. The viability of the control cells was considered as $100 \%$. Relative \% cell viability were calculated by Equation (4).

Relative viability $=[\mathrm{OD}$ of test sample - OD sample control /OD unexposed sample - OD Media] $\times 100$

\section{RESULTS AND DISCUSSION}

\section{Resistance and Susceptibility Profiling of Pathogens}

To assess multidrug resistance profiling; Enterococcus faecalis, Listeria monocytogenes and Staphylococcus aureus were tested against 14 different commercially available antibiotics and zone of inhibition of each antibiotic was measured (Figure 1). To categorize the pathogens as susceptible (S), Intermediate (I), or resistant (R); results were compared to CLSI guidelines (Table 1). E. faecalis, Listeria monocytogenes and Staphylococcus aureus were completely resistant against 1 st and 3 rd generation cephalosporins e.g., cefazolin (KF) and cefotaxime (CTX). All these pathogens were resistant to vancomycin (VA), so we can mark them as vancomycin resistant strains of enterococcus (VRE), Listeria and Staphylococcus (VRSA). The vanA and vanB genes involved in the regulation and expression of vancomycin resistance, which often reside on a plasmid, are responsible for emerging vancomycin resistance in $E$. faecalis (Greninger et al., 2016). In addition to the resistance against vancomycin, $S$. aureus was also resistant to cefoxitin (FOX), hence considered as methicillin resistant $S$. aureus (MRSA). Due to horizontal transfer of resistance genes present on the plasmid; Staphylococcus spp., E. faecalis and Listeria monocytogenes exhibited complete resistance against $\beta$-lactam antibiotic i.e., ampicillin (AMP). All pathogens demonstrated resistance against carbapenems. Multidrug resistant including vancomycin and methicillin resistant foodborne pathogens are considered as health threat of the twenty first century (Miller et al., 2016). To treat emerging antibiotic-resistance in foodborne pathogens, natural antimicrobial peptides have been suggested as a good alternative for conventional antibiotics. Among all the antimicrobial peptides (AMPs), nisin is the only class 1 bacteriocin (lanthionine-containing antibiotics) approve by FDA to be utilized as food preservatives. As a primary test for antibacterial activity, free nisin (non-encapsulated) revealed MIC value of 10, 50, and $200 \mu \mathrm{g} / \mathrm{mL}$ against Staphylococcus aureus, Listeria monocytogenes and Enterococcus faecalis, respectively. Nisin acts on bacteria by binding to lipid II (inhibit cell wall synthesis) and by pore formation on cell membrane of the targeted pathogens (Han et al., 2017; Jorge et al., 2017)

\section{Characterization of Size and Surface Charge of Nano-Antimicrobials}

Dynamic light scattering (DLS) based assays revealed that the particle size and zeta potential of empty nano-liposomes were $145 \pm 2 \mathrm{~nm}$ and $-4.37 \pm 0.16 \mathrm{mV}$, respectively, with a PDI of 0.21 . After surface engineering with layers of CTS and ALG, the size increased to $596 \pm 3 \mathrm{~nm}$ and $643 \pm 5$ with $\zeta$ potential values varied from $16.5 \pm 5.8 \mathrm{mV}$ and $33.3 \pm 6.07 \mathrm{mV}$ for chitosomes and multi-component colloidosomes, respectively (Table 2).

After encapsulation with nisin, changes in nanoparticle size were observed in NLs as well as in chitosan coated liposomes and MCCS. Average size of MCCS was increased to $844 \pm 6 \mathrm{~nm}$ after nisin encapsulation. Similarly, particle size of nanoliposmes varied from 145 to $161 \mathrm{~nm}$, which confirmed the encapsulation of nisin inside the lipid bilayer and core. Previously, it was observed that main factors influencing the average size and zeta potential of multi-component systems were $\mathrm{pH}, \mathrm{Ca}^{2+}, \mathrm{ALG}$, and CTS concentration (Li et al., 2013; Almalik et al., 2017). Moreover it was previously observed that more than $0.2 \% \mathrm{Ca}^{2+}$ ratio in ALG solution increased the particle size (Caetano et al., 2016). 

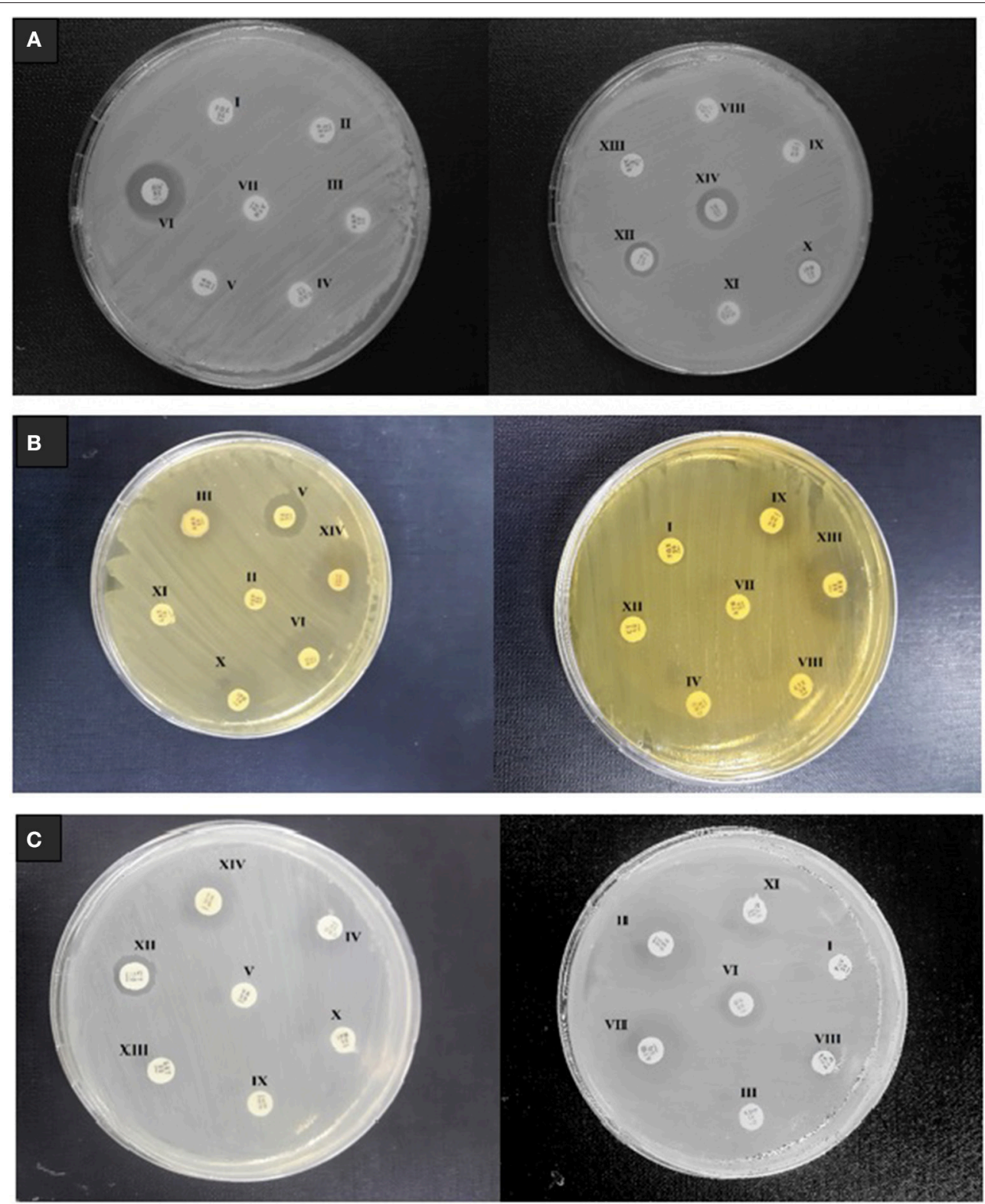

FIGURE 1 | Multi drug resistance profiling of foodborne pathogens isolated from milk samples (A) E. faecalis (B) L. monocytogenes, and (C) S. aureus. The tested discs containing different antibiotics include FOX (I) FEP (II) AMP (III) CRO (IV) VA N) MH (VI) ATM (VII) CTX (VIII) KF (IX) IPM (X) CAZ (XI) CT (XII) SXT (XIII) TE (XIV).

Zeta potential analysis revealed that MCCS were positively charged and zeta potential remain same even after nisin encapsulation. According to EE results, only $1 \%$ of nisin was encapsulated between alginate and chitosan coating in MCCS, therefore zeta potential value remained unaffected.

Positive zeta potential value of MCCS could be due to positively charged $\mathrm{Ca}^{2+}$ ion and chitosan. At the beginning, colloidal suspension appeared negatively charged due to the adsorption of anionic ALG. However, after addition of $\mathrm{CaCl}_{2}$, the value of zeta potential becomes positive (Chandrasekar et al., 2017). Moreover, when Chitosan concentration was over $0.48 \%$, zeta potential varied toward a drastic positive charge because of excessive chitosan and $\mathrm{Ca}^{2+}$ cross-linking (Cheng et al., 2015). Most significantly, zeta potential analysis indicated that relatively higher positive charge of MCCS as compared to NLs or chitosomes can not only contribute toward the stability of nano-formulation but also help in the interaction of NCS with negatively charged bacterial pathogens.

\section{Physical Stability Analysis}

To ensure physical stability of nano-antimicrobials; particle size, PDI and zeta potential analyses were performed (Figure 2). 
TABLE 1 | Resistance profiling of foodborne pathogens against tested antibiotics.

\begin{tabular}{|c|c|c|c|c|}
\hline \multirow[t]{2}{*}{ Antimicrobial agent } & \multirow[t]{2}{*}{ Disc content $(\mu \mathrm{g})$} & \multicolumn{3}{|c|}{ Inhibition zone diameter (mm) } \\
\hline & & S (Sensitive) & I (Intermediate) & R (Resistant) \\
\hline Cefoxitin (FOX) & 30 & $\geq 23$ & - & - \\
\hline Cefepime (FEP) & 30 & $\geq 18$ & $15-17$ & $\leq 14$ \\
\hline Ampicillin (AMP)/Amoxicillin (AMC) & $10 / 30$ & $\geq 22$ & $19-21$ & $\leq 18$ \\
\hline Ceftriaxone (CRO) & 30 & $\geq 26$ & - & - \\
\hline Vancomycin (VA) & 30 & $\geq 17$ & $15-16$ & $\leq 14$ \\
\hline Minocycline (MH) & 30 & $\geq 19$ & $15-18$ & $\leq 14$ \\
\hline Aztreonam (ATM) & 30 & $\geq 26$ & $18-20$ & $\leq 17$ \\
\hline Cefotaxime (CTX) & 30 & $\geq 26$ & - & - \\
\hline Cephalothin (KF) & 30 & $\geq 15$ & - & - \\
\hline Imipenem (IPM) & 10 & $\geq 19$ & $16-18$ & $\leq 15$ \\
\hline Ceftazidime (CAZ) & 30 & $\geq 18$ & $15-17$ & $\leq 14$ \\
\hline Colistin sulfate (CT) & 10 & $\geq 17$ & $10-16$ & $\leq 11$ \\
\hline Sulphamthoxazole/trimethoprim (SXT) & $1.25 / 23.75$ & $\geq 16$ & $11-15$ & $\leq 10$ \\
\hline Tetracycline (TE) & 30 & $\geq 19$ & $15-18$ & $\leq 14$ \\
\hline
\end{tabular}

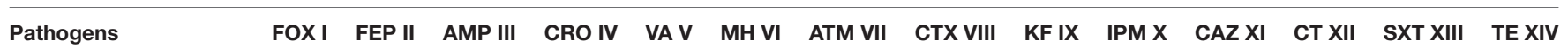

\begin{tabular}{|c|c|c|c|c|c|c|c|c|c|c|c|c|c|c|}
\hline \multicolumn{15}{|c|}{ ZONE OF INHIBITION (MM) } \\
\hline E. faecalis & - & - & - & - & - & 18 & - & - & - & - & - & 10 & - & 12 \\
\hline L. monocytogenes & - & 25 & - & 24 & 10 & 14 & 22 & - & - & 13 & 20 & 24 & 17 & 22 \\
\hline S. aureus & - & 12 & - & - & - & 10 & 13 & - & - & - & 12 & 10 & - & 11 \\
\hline
\end{tabular}

Disk diffusion quality control range for pathogens according to CSLI guidelines 2017.

TABLE 2 | Average size, PDI (polydispersity index), $\zeta$ potential and encapsulation efficiency of empty and nisin loaded liposomes, chitosan coated liposomes (chitosomes) and multicomponent colloidosomes with standard deviation values $(n=3)$.

\begin{tabular}{lcccc}
\hline Nano formulations & $\begin{array}{c}\text { Size } \\
\mathbf{n m} \pm \mathbf{S D}\end{array}$ & PDI & $\begin{array}{c}\zeta \text { potential } \\
(\mathbf{m V} \pm \mathbf{S D})\end{array}$ & EE\% \\
\hline Void liposomes & $145 \pm 2$ & 0.21 & $-4.37 \pm 0.16$ & - \\
Void chitosomes & $596 \pm 3$ & 0.24 & $16.5 \pm 5.80$ & - \\
Void multicomponent & $643 \pm 5$ & 0.19 & $33.3 \pm 6.07$ & - \\
colloidosomes & $161 \pm 2$ & 0.15 & $-3.47 \pm 0.13$ & $56.53 \pm 2.5 \%$ \\
Nisin-liposome & $768 \pm 5$ & 0.24 & $33.0 \pm 5.21$ & $82.43 \pm 1.5 \%$ \\
Nisin-chitosomes & $844 \pm 6$ & 0.25 & $33.3 \pm 4.07$ & $83.35 \pm 2.2 \%$ \\
Nisin-multicomponent & & & & \\
colloidosomes & & & &
\end{tabular}

Visual changes in appearance of different nano-formulations (NLs, CS, MCCS) with or without nisin were studied after storage at room temperature for 3 weeks as well (Figure 2D). It was observed that all the nanocarriers systems remained stable during first week as no drastic change in average size was observed after 7 days. However, after 2 and 3 weeks of storage, remarkable increase in size was observed in blank as well as nisin loaded nanoliposomes (145 \pm 2 to $811 \pm$ 4.1 and $161 \pm 2$ to $790 \pm 3.9$, respectively). On the other hand, CS and MCCS remained stable during this period as size distribution data had not displayed significant variation (Figure 2A).
Polydispersity index (PDI) is an important parameter to determine the size heterogeneity of the dispersions during storage. PDI data of nano-formulations indicated better stability of CS and MCCS than NLs, as PDI was found to be less than 0.3 in both chitosomes and MCCS with or without bacteriocin, thereby signifying the presence of monodispersed NCS (Figure 2C). However, PDI was $>0.4$ for uncoated nanoliposomes indicating the formation of aggregates during storage. This aggregation or phase separation in NLs was also visually observed after 21 days (Figure 2D).

ZP indirectly determines the stability of nano-colloidal systems. Negative zeta potential of NLs is due to negatively charged phosphate groups in the head group of phospholipids (Bhattarai et al., 2016). The magnitude of the negative zeta potential on NLs decreased with time (Figure 2B), which might be due to release of positively charged nisin in the solution and due to less availability of negatively charged phosphate group after aggregation. No significant variations in $\mathrm{ZP}$ were noticed in void and nisin loaded multicomponent colloidosomes which confirmed their physical stability.

\section{Measurement of Encapsulation Efficiency (EE \%)}

Size of the NCS, chemical structure, composition of polymers and active agent are the main factors affecting encapsulation efficiency of any NCS. Smaller the size, lower will be the $\mathrm{EE} \%$ and vice versa. EE\% of nisin loaded multicomponent 
A

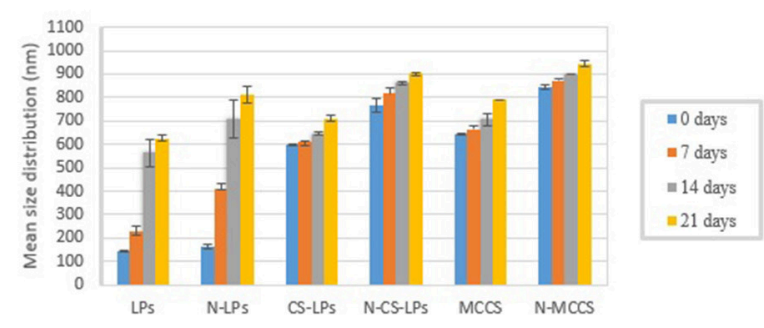

C

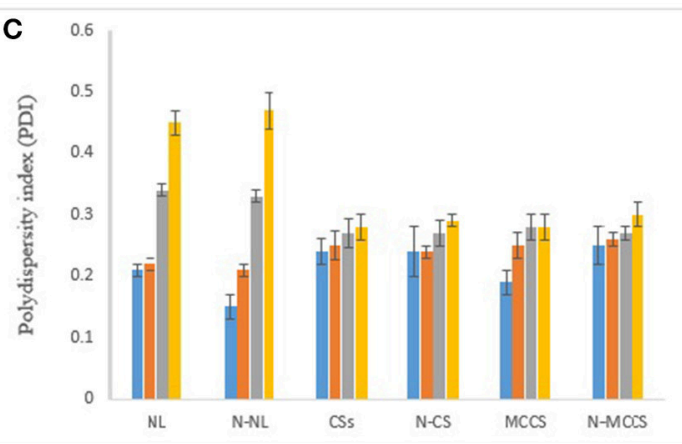

B

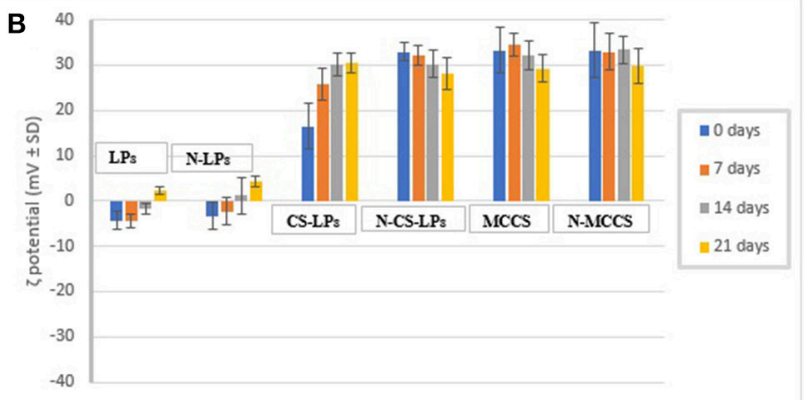

D

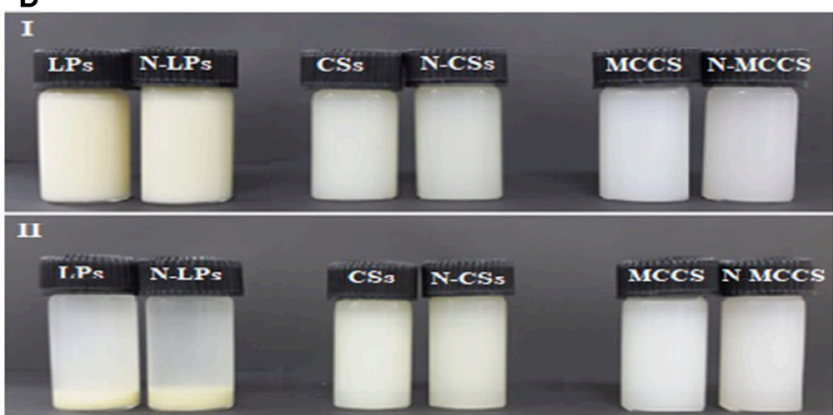

FIGURE 2 | Stability analysis of NLs (Nano liposomes), N-LPs (Nisin loaded liposomes), CSs (blank chitosomes), N-CSs (Nisin loaded chitosomes), MCCS (blank multicomponent colloidosomes) and N-MCCS (nisin loaded multicomponent colloidosomes), over a period of 21 days. Considering the variables: (A) size, (B) zeta potential, (C) PDI, and (D) appearance (where 0 refers to day of fabrication, and 1, 2, and 3 refer to time in weeks).

nanoparticles was $83 \pm 2.2 \%$. Thus, the EE\% of nisin for MCCS was almost equal to chitosomes $(82 \pm 1.5 \%)$ but relatively higher than nano-liposomes $(56 \pm 2.5 \%)$ (Table 2). Nisin entrapment efficiency depends on the interaction between outer layer of liposome and chitosan; as well as extent of cross linking between alginate, CTS polymer and divalent cation $\left(\mathrm{Ca}^{+2}\right)$. In MCCS, crosslinking between the two biopolymers occurred due to free $\mathrm{NH}_{2}$ group of CTS and $-\mathrm{COOH}$ or $-\mathrm{OH}$ groups of alginate. This crosslinking increases the stability of multicomponent NCS, makes them less porous for the release of nisin. Therefore, free nisin (which was not entrapped in liposomes) was embedded in the three-dimensional polyelectrolyte shell during coating with polymers. Moreover, nisin $\mathrm{Z}$ contains terminal amino group of isoleucine and terminal carboxyl group of lysine which possess pKa values of 9.68 and 2.18 , respectively. Nisin $\mathrm{Z}$ is more soluble at near neutral or acidic $\mathrm{pH}$. At this $\mathrm{pH}$ range (2.5-6.5), ionization of the carboxyl group occurs due to which solubility of nisin increases. At basic $\mathrm{pH}$ above 7 , deprotonation of terminal amino groups decreases the protein solubility and reduces its positive charge. As a result, reduction in electrostatic interaction between nisin and oppositely charge molecules was observed (Gharsallaoui et al., 2016; Khan and Oh, 2016). Secondly, structural modification in nisin $\mathrm{Z}$ starts at basic $\mathrm{pH}$ and above its isoelectric point (pI, 7). These modifications occur rigorously via intra molecular interactions, which render nisin less available for interactions with polymer. Thus, these modifications result in reduced $\mathrm{EE} \%$ as well as antimicrobial efficiency of nisin. As the $\mathrm{pKa}$ values of chitosan and alginate
(6.2-7 and 3.4-4.4, respectively) (Seeli et al., 2016) are existing in the solubility range of nisin, it resulted in better interaction of nisin with these carbohydrate based polymers. The presence of protonated carboxyl groups could promote the electrostatic or hydrophobic interactions of nisin with polymers in the acidic solution, thus increasing its encapsulation efficiency. As previously reported, the reduction in $\mathrm{pH}(6.6-3.6)$ demonstrated a positive effect on the amount of nisin entrapped in the polymeric delivery systems (Krivorotova et al., 2016). Therefore, it is concluded that relatively lower $\mathrm{pH}$ and hydrophobicity of nisin controlled the interaction of nisin with biopolymer, which is reflected in relatively higher encapsulation efficiency of nisin in MCCS.

\section{Scanning Electron Microscopy (SEM) of Multilayer Colloidosomes}

SEM was performed for the morphological characterization of MCCS. Microscopic images revealed that multicomponent NCS with and without nisin were round and smooth in appearance (Figures 3I-IV). Crystalline structures were not observed on the surface of nisin loaded NCS, which indicated that the active peptides were entrapped inside the colloidal system. Size of the multicomponent carrier system ranged from 800 to $900 \mathrm{~nm}$ due to multilayer polymer coating on nano-liposomes. Increase in size could be attributed to the gelation and swelling property of alginate during air-drying of samples on glass-slides before carbon coating. 

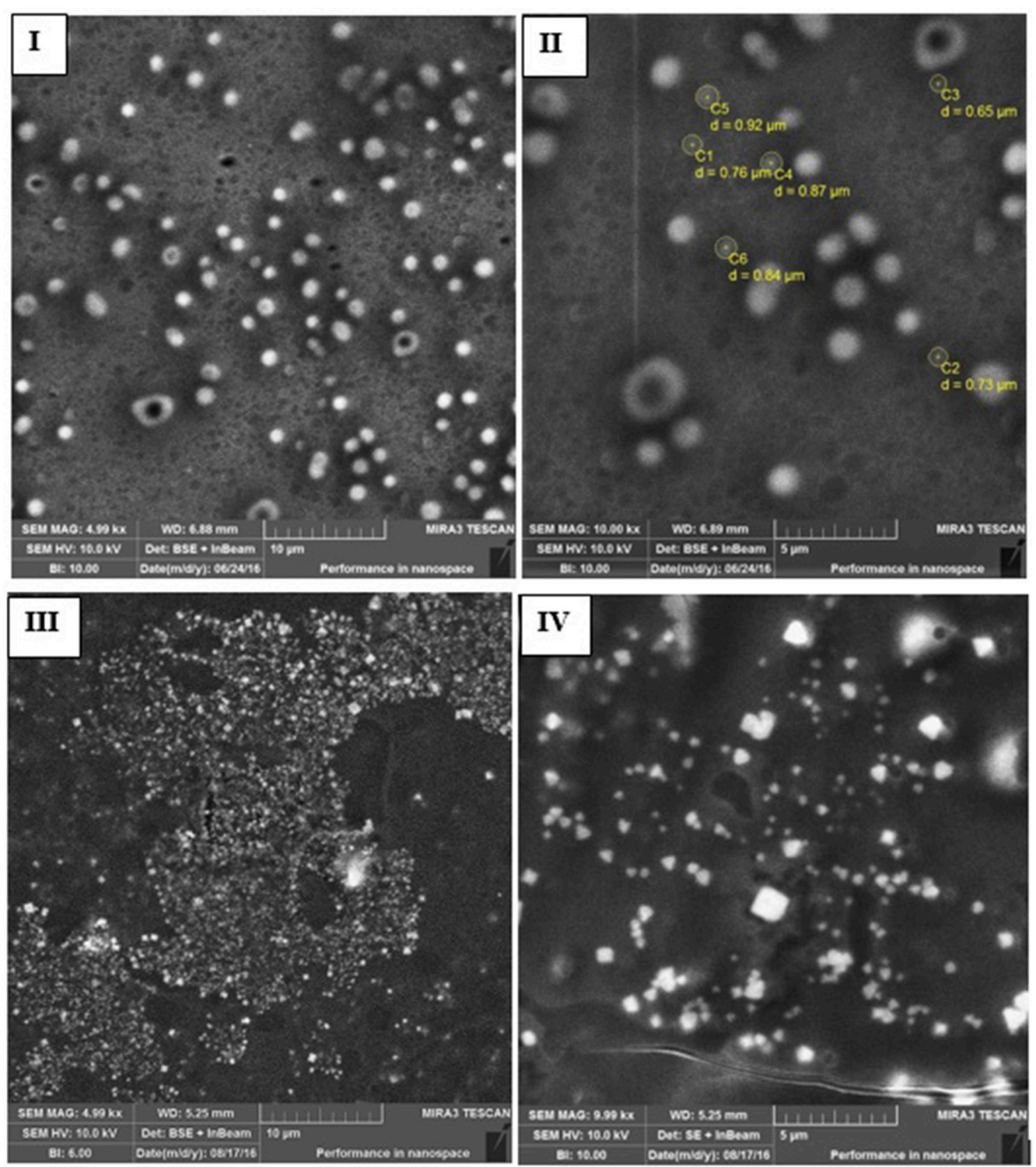

FIGURE 3 | Scanning electron microscopy (SEM) images of blank and nisin encapsulated multicomponent systems including nisin loaded MCCS (I,II) and void MCCS (III,IV).

\section{Differential Scanning Calorimetry (DSC)}

Phase transition and physical aging of nisin and polymer as pure compound and nano-antimicrobial formulations were determined by DSC analyses. In thermogram of sodium alginate, initial endothermic peak was observed at $110^{\circ} \mathrm{C}$, whereas higher exothermic peaks were observed at $189^{\circ} \mathrm{C}$ and $285^{\circ} \mathrm{C}$, respectively. Endothermic peaks are correlated with loss of water linked to hydrophilic groups of polymer while exothermic peaks resulted from degradation, dehydration and depolymerization reactions, which are most probably due to partial decarboxylation and oxidation reactions of the $-\mathrm{COOH}$ groups present in sodium alginate (El-Houssiny et al., 2016).

Phase transition in empty MCCS was observed from 67 to $98^{\circ} \mathrm{C}$ which was not present in nisin loaded multicomponent NCS (Figure 4). In DSC analysis of multicomponent NCS, a decrease in melting endotherm $(\mathrm{Tm})$ was observed from $117^{\circ} \mathrm{C}$ in blank NCS to $115^{\circ} \mathrm{C}$ in nisin loaded MCCS which could be referred to the cleavage of hydrogen bonds during nisin encapsulation in NCS. Formation of hydrogen bonds in the crystallization phase occurred at $150.5^{\circ} \mathrm{C}$. This could be due 

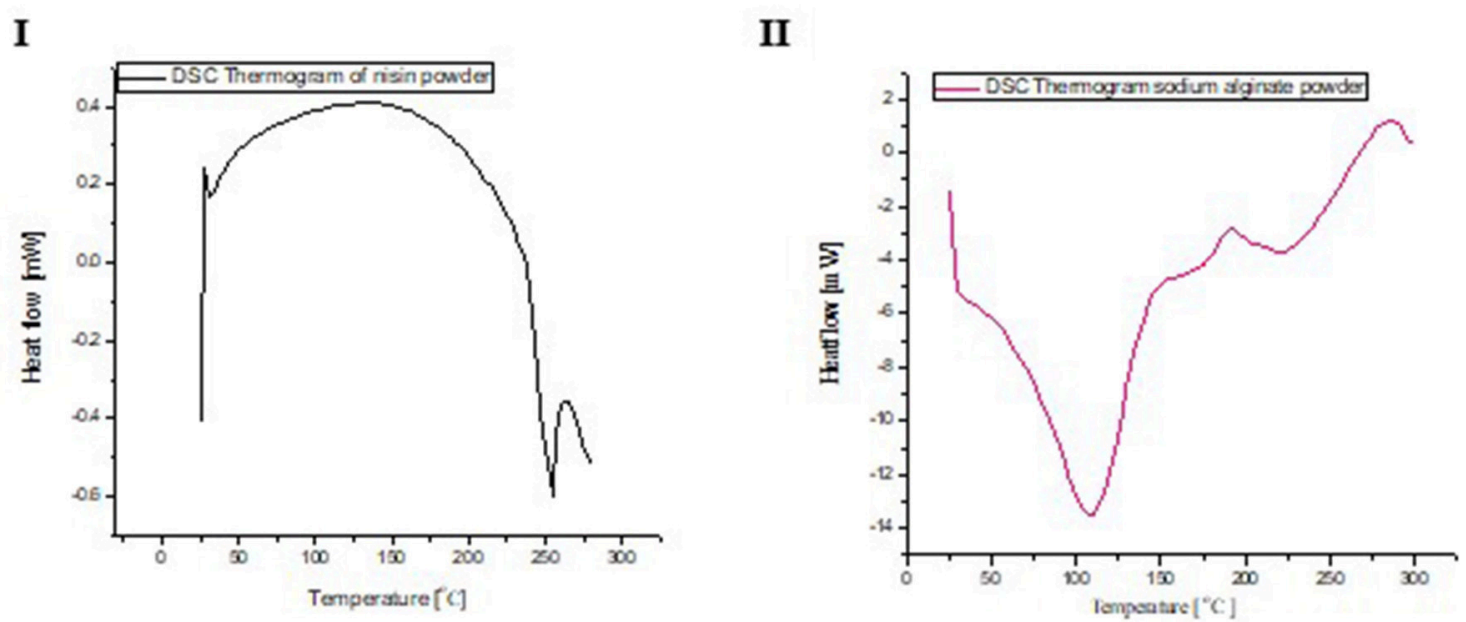

III

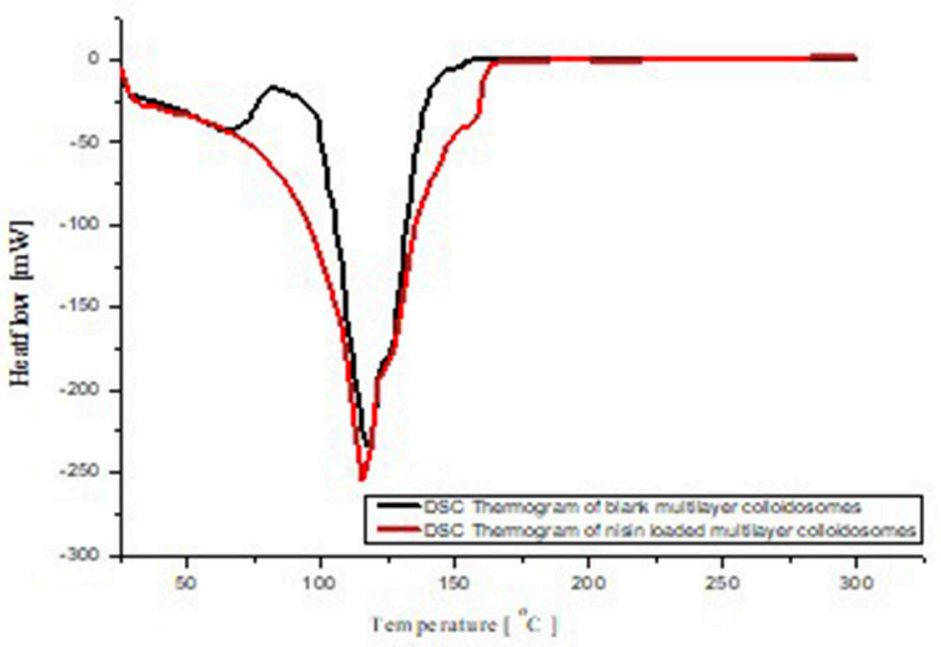

FIGURE 4 | DSC analyses of nisin (I), sodium alginate (II), comparison of DSC curve between void and nisin loaded NCS (III).

to degradation of alginate layer at this high temperature, thus exposing the CTS layer. In case of active agent loaded NCS, crystallization endotherm was registered at $158^{\circ} \mathrm{C}$ which was not very different from blank NCS. This observation confirmed that very low amount of active agent was present between alginate and chitosan layer (Furuya et al., 2017). Once alginate layer degraded at high temperature, it exposed more amorphous content (nisin and chitosan), which increased the temperature value for crystalline endotherm.

\section{Thermo Gravimetric Analysis (TGA)}

TGA curves of nisin, alginate and multicomponent colloidosomes are shown in (Figure 5). In TGA analysis of pure nisin, a single major thermal degradation peak was observed at $259^{\circ} \mathrm{C}$. However TGA curve of sodium alginate showed three peaks; first peak initiated at $32^{\circ} \mathrm{C}$ and continued till $92^{\circ} \mathrm{C}$ corresponding to $1.8 \%$ weight loss which can be attributed to the loss of moisture (Pandey and Ramontja, 2016). The second shift in curve appeared at $257^{\circ} \mathrm{C}$ attributing to the major weight loss of almost $13 \%$ due to breaking up of $\mathrm{C}-\mathrm{H}$ bonds, which refers to the decomposition and degradation of the biopolymer. This decomposition peak initiated from $198^{\circ} \mathrm{C}$ and continued until $363^{\circ} \mathrm{C}$. Furthermore, $2 \%$ weight loss was observed during third shift in the TGA peak of ALG, which initiated from $364^{\circ} \mathrm{C}$ and continued until $591^{\circ} \mathrm{C}$. Overall, for sodium alginate powder, the gradual mass loss in TGA curve was observed from $92^{\circ} \mathrm{C}$ to $363^{\circ} \mathrm{C}$.

Similarly, in multilayer NCS, mass loss due to water evaporation was observed in both blank and nisin loaded nanoparticles. Second phase of mass loss was observed before $349^{\circ} \mathrm{C}$, which was not observed (negligible) in blank multicomponent nanocarrier systems. No kink or dip for nisin decomposition $\left(259^{\circ} \mathrm{C}\right)$ was observed in the TGA curve, which means nisin is not encapsulated between the alginate meshwork, 
rather it is encapsulated between the core and internal layer of multicomponent colloidosomes. Thus, multilayer coating on nano-liposomes slightly increase the thermal stability, which is in coherence with previous findings for anticancer drug encapsulation system (Manatunga et al., 2017). Insignificant difference was seen in the thermogram of both blank and nisin loaded multicomponent colloidosomes which could be due to the fact that positively charged chitosan and calcium ions can potentially compete with each other for available carboxylic acid

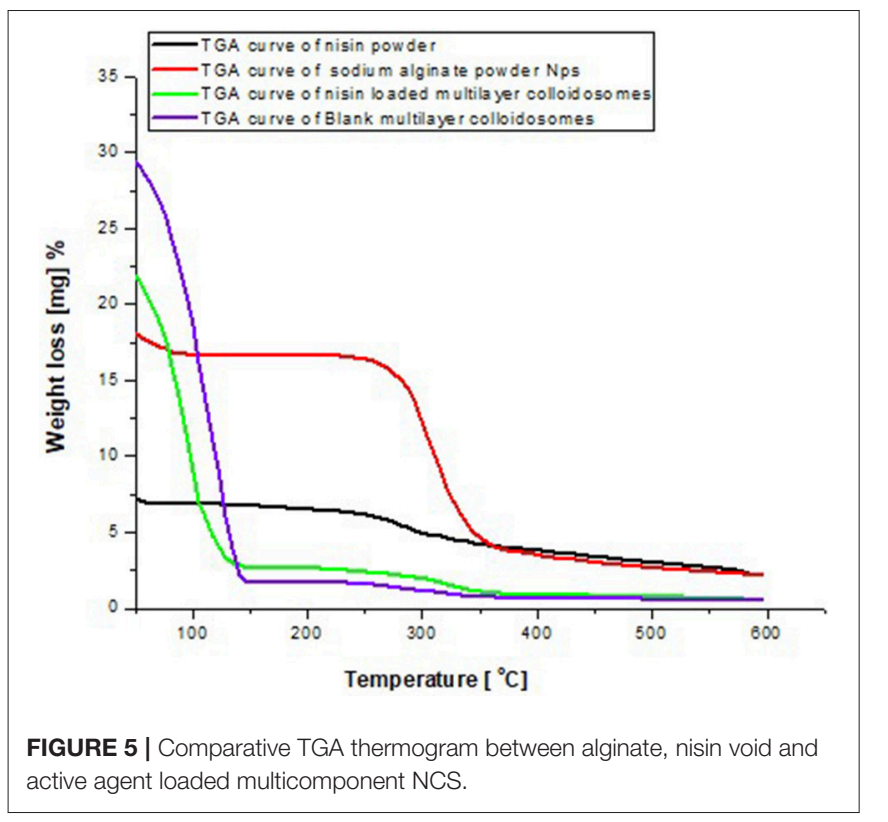

sites on the alginate, leaving less pace for nisin to encapsulate in the outer layer of alginate on CS (George and Abraham, 2006). This hypothesis can also be verified from \%EE data. Hence nisin is encapsulated either in the core and bilayer of liposomes or in the CTS layer on the surface of nano-liposomes.

\section{Fourier Transformed Infrared Spectroscopy (FTIR)}

Figure 6 illustrates the FTIR spectra for nisin, alginate (surface layer) and multi-component colloidosomes (MCCS) as an entire carrier system. In FTIR spectral analysis of nisin powder, four major characteristics peaks appeared at 3,288, 3,001, 1,650, and $1,522 \mathrm{~cm}^{-1}$; which were attributed to $\mathrm{O}-\mathrm{H}$ asymmetrical stretch, C-H symmetrical stretching, amide group, and to the bending of primary amines respectively. Sodium alginate displayed major characteristic peaks of $\mathrm{O}-\mathrm{H}$ stretching at 3,438 $\mathrm{cm}^{-1}$, C-H stretching of the $\mathrm{CH}_{2}$ groups at $2,121 \mathrm{~cm}^{-1}$, carboxylate salt group (asymmetric stretching) at 1,652 $\mathrm{cm}^{-1}$, carboxylate salt group (week symmetric stretching) at 1,417, $\mathrm{C}-\mathrm{H}$ stretching peak at 2,885 and $\mathrm{C}-\mathrm{O}-\mathrm{C}$ stretching at 1,186 $\mathrm{cm}^{-1}$. As described previously by $\mathrm{Niaz}$ et al., four major characteristic peaks at 3,398,2,878,1,654, and $1,379 \mathrm{~cm}^{-1}$ are due to the $\mathrm{N}-\mathrm{H}, \mathrm{C}-\mathrm{H}$, amide I and amide III groups respectively in the chitosan FTIR spectra (Niaz et al., 2016). In case of blank multicomponent colloidosomes, widening of carboxylate stretching peak with slightly shifted to lower wave numbers, which could possibly be the result of cross-linking between ALG and chitosan polymers. Furthermore, all characteristic peaks present in blank MCCS are also present in nisin loaded multicomponent systems. But all these spectral peaks shifted to lower wavenumber, which might be due to gelatinization

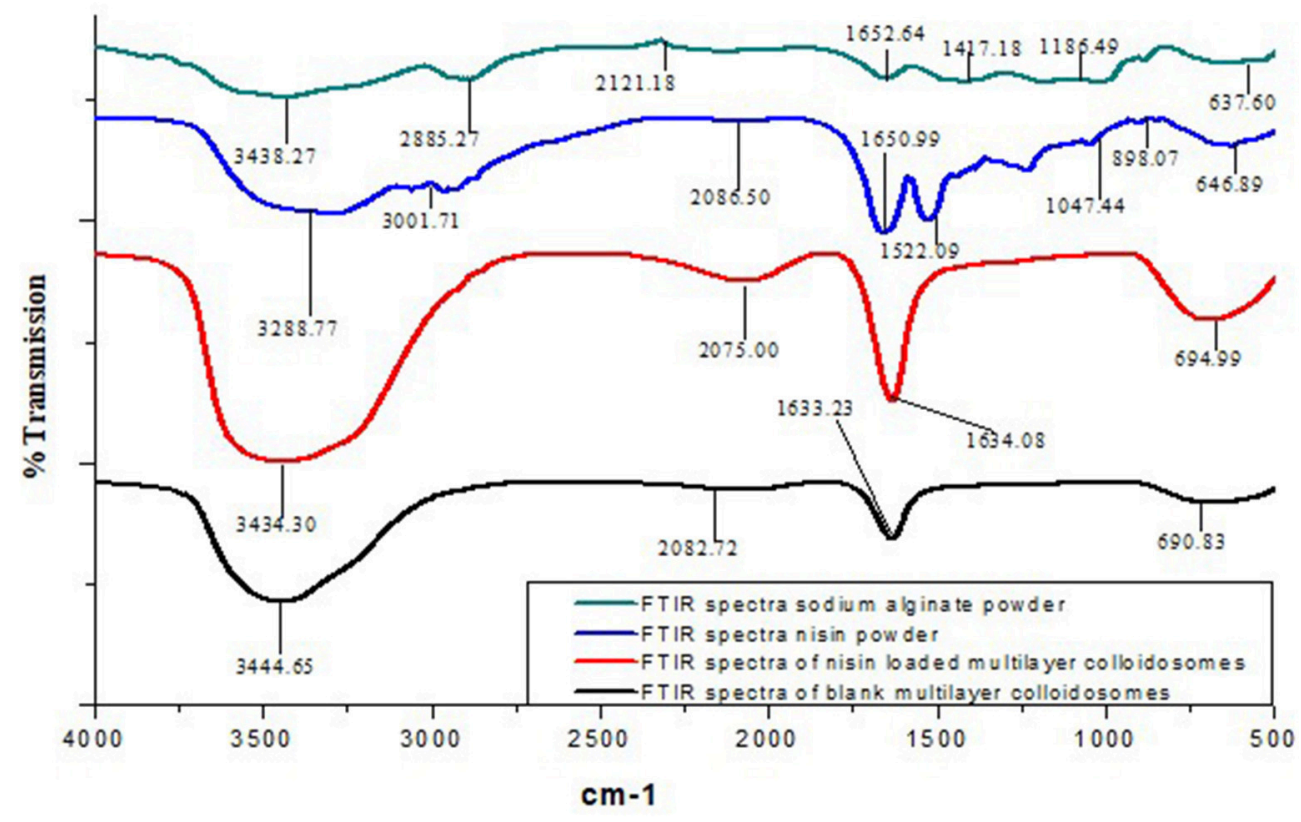

FIGURE 6 | Comparative FTIR analysis of multicomponent NCS, pure powdered form of sodium alginate (outer layer), nisin powder and nisin loaded MCCS. 


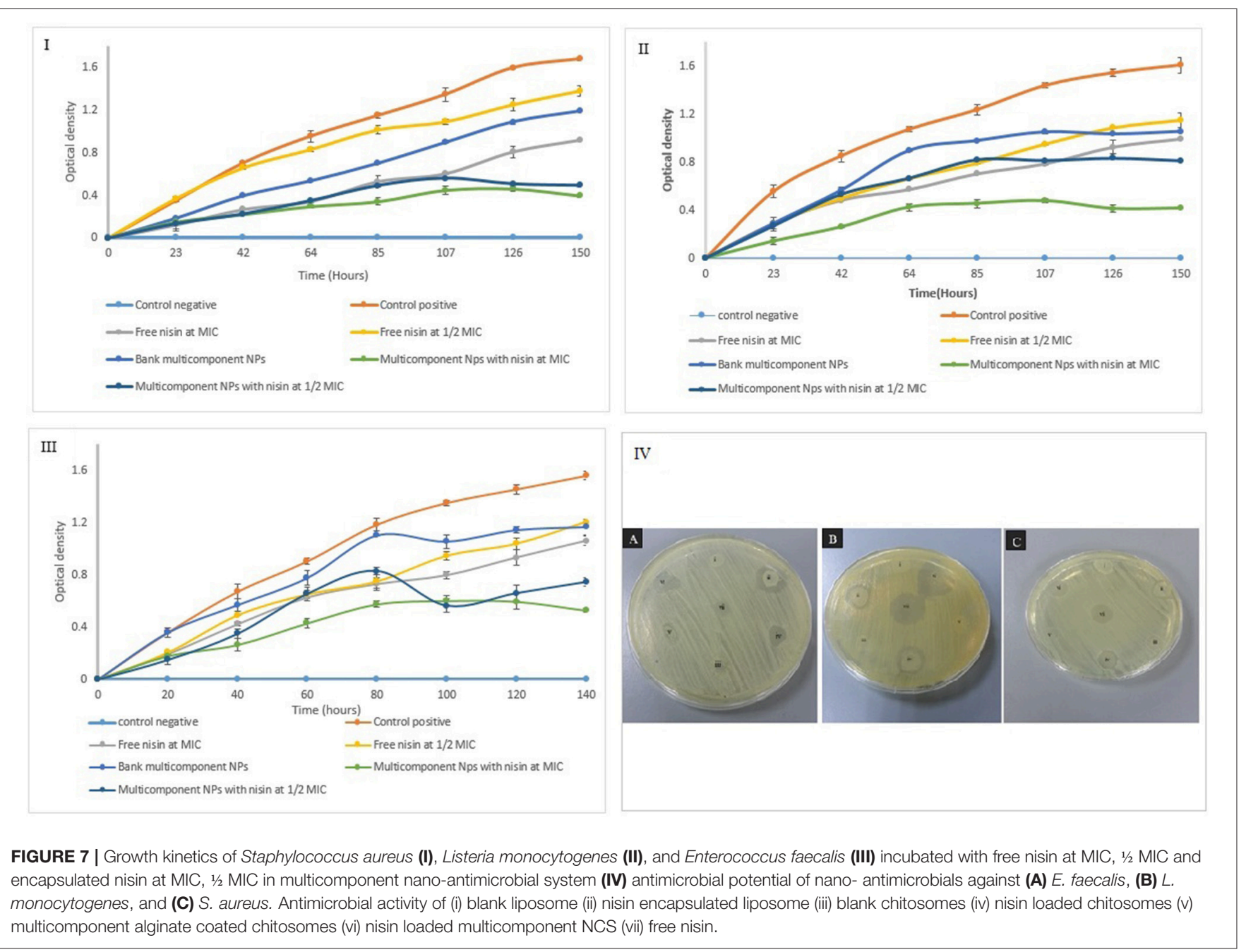

property of alginate. Furthermore, no new peak appeared in nisin loaded MCCS, thus confirming that there is no chemical interaction between encapsulated nisin and alginate polymer. This observation supports the concept that nisin was not attached on the surface but encapsulated inside the polymer layer or inner core.

\section{In Vitro Antimicrobial Activity of Nano-Antimicrobials}

Efficacy of different nisin loaded nano-carrier systems and their controls against selected foodborne pathogens (Staphylococcus aureus, Listeria monocytogenes, and Enterococcus faecalis) was tested on inoculated agar medium (Figures 7IVA-C). As predicted, void liposomes had not demonstrated any inhibition zone. However, in case of CTS coating on nanoliposomes (chitosomes) and alginate coated chitosomes (MCCS); small inhibition zones were observed owing to antibacterial activity of chitosan polymer. Active carrier-systems containing antimicrobial peptide nisin had generated larger inhibition zones due to release and diffusion of nisin in the agar network from colloidal systems. Active formulations of liposomes, chitosomes and multicomponent colloidosomes had exhibited better control of pathogen as compared to controls.

\section{Growth Kinetics of Resistant Pathogens: Potential of Nano-Antimicrobials}

Afterwards, growth kinetics of selected pathogens were carried out under the influence of either free nisin or encapsulated in multi-component colloidosomes. Different solutions including control (without nisin addition), free nisin solution (MIC and $1 / 2$ MIC), encapsulated nisin in MCCS at corresponding MIC and $1 / 2$ MIC value were tested for antimicrobial activity against above-mentioned foodborne pathogens. As expected, the control sample without nisin had not shown antimicrobial action against all three resistant pathogens. Free nisin (MIC value and $1 / 2$ MIC) inhibited bacterial growth up to $24 \mathrm{~h}$ but afterwards gradual and steady growth of bacteria was observed. However, the reduction of nisin concentration to $1 / 2$ MIC did not control the increase in bacterial population as much as $1 / 2$ MIC concentration of nisin in nano-encapsulated form.

Against Staphylococcus aureus, active multilayer nanoantimicrobials demonstrated better activity at $1 / 2$ MIC 


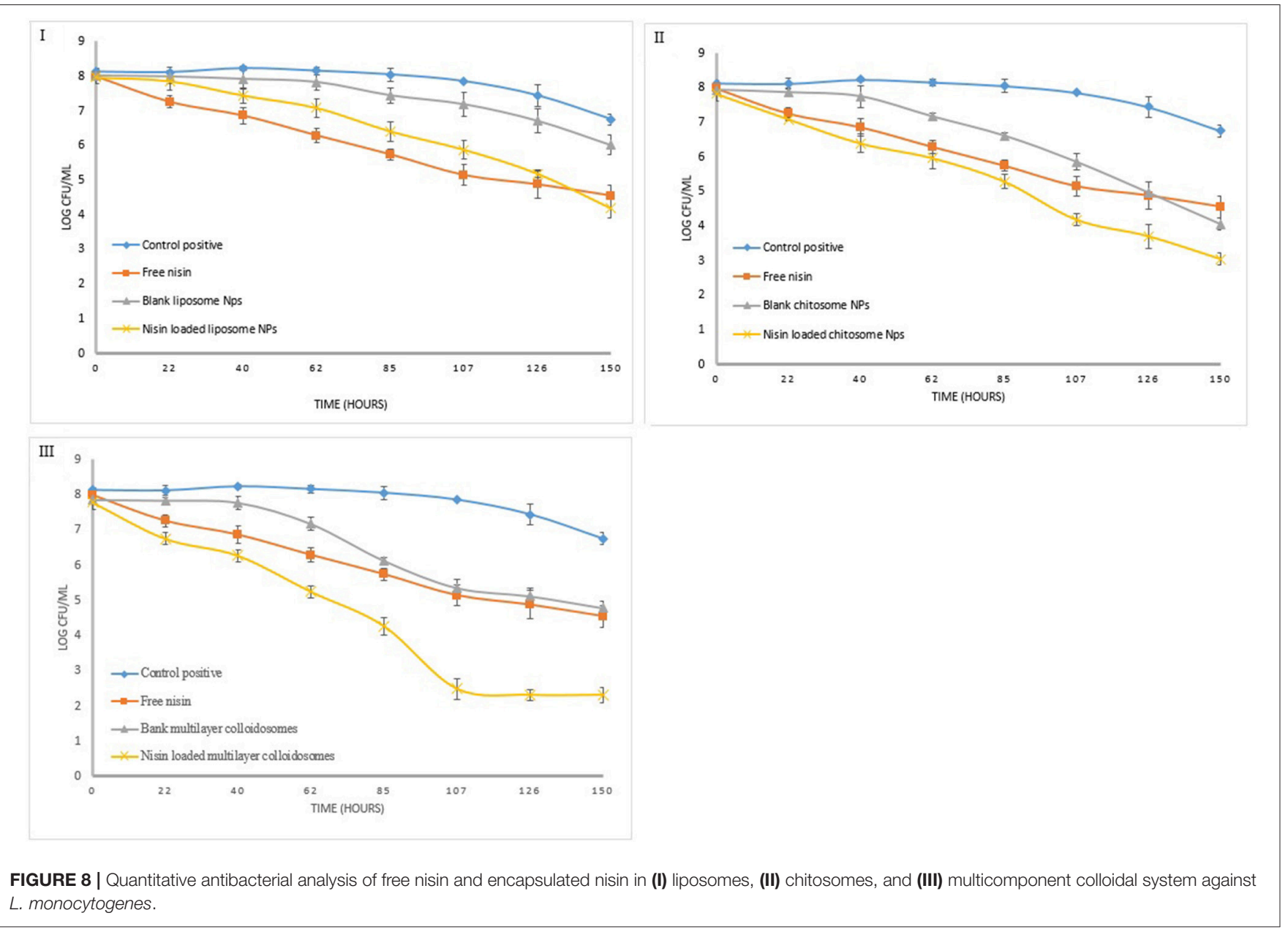

concentration than free nisin at full MIC (Figure 7I). This reduction in pathogen growth was due to slow release of nisin initially from alginate-chitosan layer, secondly from chitosanliposomes layer after swelling of alginate layer in the medium (Lopes et al., 2016) and then burst release after 5th day from liposome core.

Antibacterial activity of formulated NCS were also tested against L. monocytogenes (Figure 7II). It was observed that multicomponent NCS loaded with nisin at $1 / 2$ MIC $(25 \mu \mathrm{g} / \mathrm{mL})$ concentration as well as void NCS controlled the bacterial growth similar to free nisin at identical concentration. Due to gelling property of ALG, bacterial growth was hindered even by blank MCCS. Similar observations have also been reported in the previous study, showing slower growth rate and narrower growth boundaries for $L$. monocytogenes in gelling agent e.g., sodium alginate and gelatin (Aspridou et al., 2014). However, an increase in bacterial growth was observed after 2 days due to alginate degradation in liquid medium, subsequently sustained growth was observed till 1 week. As expected, active multicomponent colloidosomes containing nisin at MIC controlled the bacterial growth almost double than free nisin at similar concentration. This could be attributed to the controlled and sustained release of bacteriocin from multilayered colloidosomes as well as synergistic antibacterial effect of CTS and nisin.

Activity of MCCS with and without active agent against $E$. faecalis was tested (Figure 7III) and it was observed that blank MCCS did not control bacterial growth during initial phase. After $42 \mathrm{~h}$, slight decrease in bacterial growth was observed than positive control. Due to bacteriostatic, gelatinizing and antibacterial property of ALG, sol-gel transition occurred which stressed the microorganism and resulted in decreased growth rate (Szekalska et al., 2016). However, after 4 days empty multicomponent systems could control the bacterial growth as much as $1 / 2$ MIC of free nisin because of exposed chitosan layer. Similar behavior was observed with $1 / 2$ MIC $(100 \mu \mathrm{g} / \mathrm{mL})$ encapsulated nisin in multicomponent systems. Though after 4 days, progressive increase in swelling leads to disintegration of alginate coating, which exposes chitosan layer (Mukhopadhyay et al., 2016). Consequently, synergistic antibacterial effect of CTS and encapsulated nisin further reduced the bacterial growth.

Active MCCS containing nisin at MIC $(200 \mu \mathrm{g} / \mathrm{mL})$ controlled the growth of $E$. faecalis almost twice than free nisin at identical concentration due to sustained release of bacteriocin from multilayers system. 

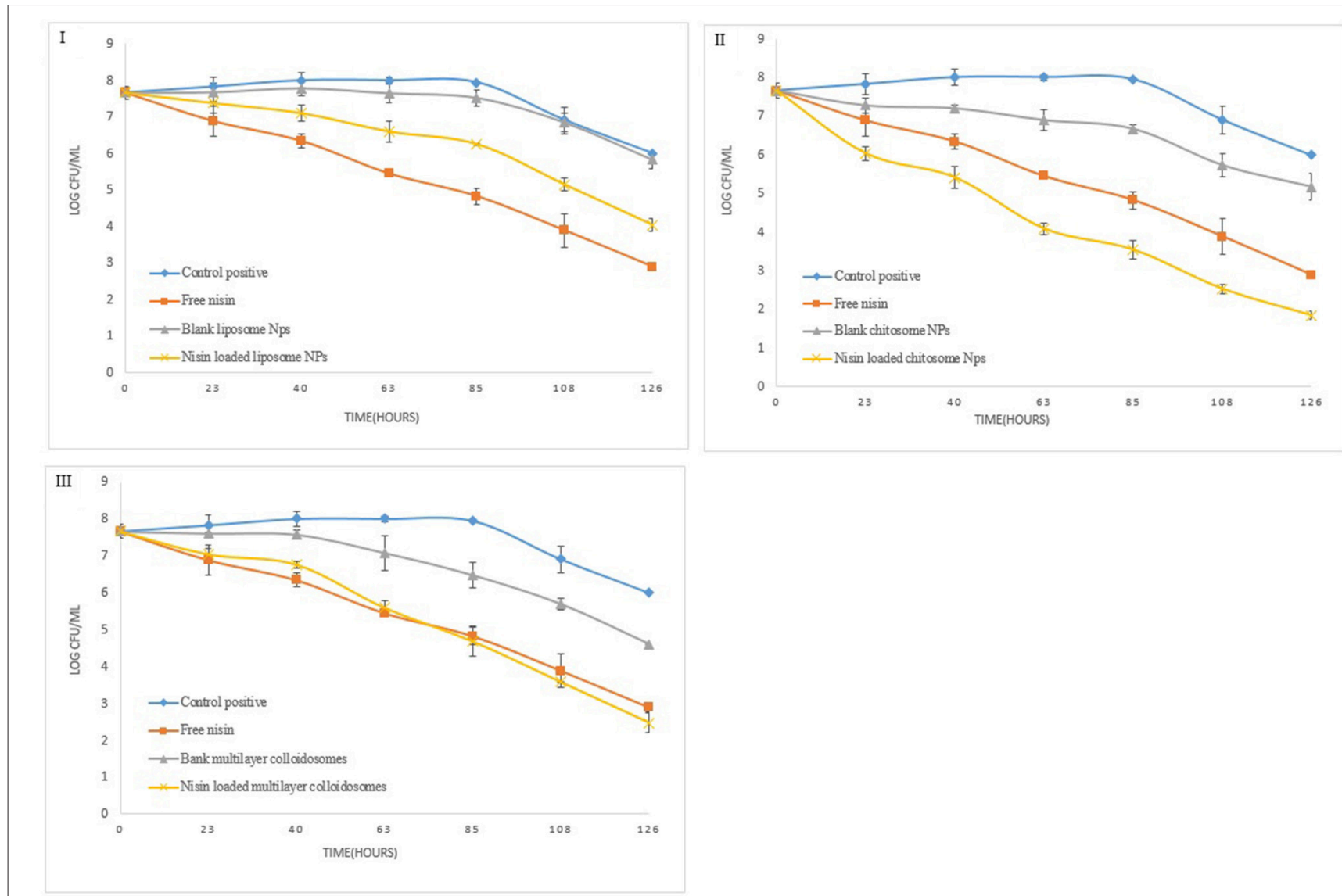

FIGURE 9 | Quantitative antibacterial analysis of free and encapsulated nisin in (I) liposome, (II) chitosome, and (III) multicomponent colloidal system against S. aureus.

\section{Quantitative Analysis of Nano-Antimicrobials' Potential}

Figure 8 reveals the data observed during the quantitative antibacterial evaluation of Listeria monocytogenes by free nisin and various non-active and active nano-systems for 1 week. Positive control referred to bacterial growth in nutrient broth without any empty and active colloidal system. After $24 \mathrm{~h}$ of exposure, nanoliposome containing nisin did not reduce

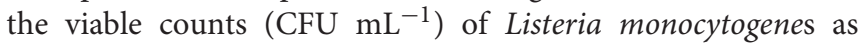
compared to free nisin which was able to reduce it by more than $1.5 \log$ units.

Blank chitosomes decreased the bacterial count similar to free nisin after 1 week which is $3.4 \log$ unit. However nisin loaded chitosomes reduce bacterial count by 4.8 log unit owing to controlled release of nisin from CTS coated liposomes, more encapsulation efficiency of chitosomes than liposomes and synergistic antimicrobial effect of chitosan and nisin ( $\mathrm{Hu}$ et al., 2017).

Active multicomponent colloidosomes reduced the bacterial count by more than $1 \log$ unit after $24 \mathrm{~h}$. More than 2 $\log$ reductions in Listeria count was observed from 4 th to 5 th day, which might be due to burst release of nisin from multicomponent colloidosomes once alginate layer was degraded. Whereas, blank multicomponent nano-systems fail to control Listeria growth initially but once alginate layer disintegrated, exposed chitosan layer reduced the bacterial count for more than $2 \log$ units.

In quantitative antibacterial analysis for $S$. aureus, active liposomes did not exhibit good control as compared to free nisin at similar concentration (Figure 9). Total $1.5 \mathrm{log}$ unit reduction in viable bacterial count was observed in first 5 days. Nevertheless, $2.5 \log$ unit reduction in the bacterial count was observed in last 2 days due to controlled released of nisin, which is in coherence with the trend observed previously (Alishahi, 2014).

Chitosan coated liposomes demonstrated good control against S. aureus (Figure 9), as within $24 \mathrm{~h}$ almost $2 \mathrm{log}$ unit reduction in the bacterial growth was observed. Though with free nisin, only 1 -unit log reduction was observed. Continuous release of nisin and chitosan's antibacterial activity resulted in total $5.8 \mathrm{log}$ unit reduction in the bacterial growth. Multicomponent NCS controlled the bacterial growth just like free nisin, however after 5th day relatively more reduction in pathogen count was observed than free nisin. These results correlate well with in vitro growth kinetics of $S$. aureus under the influence of nano-antimicrobials. 

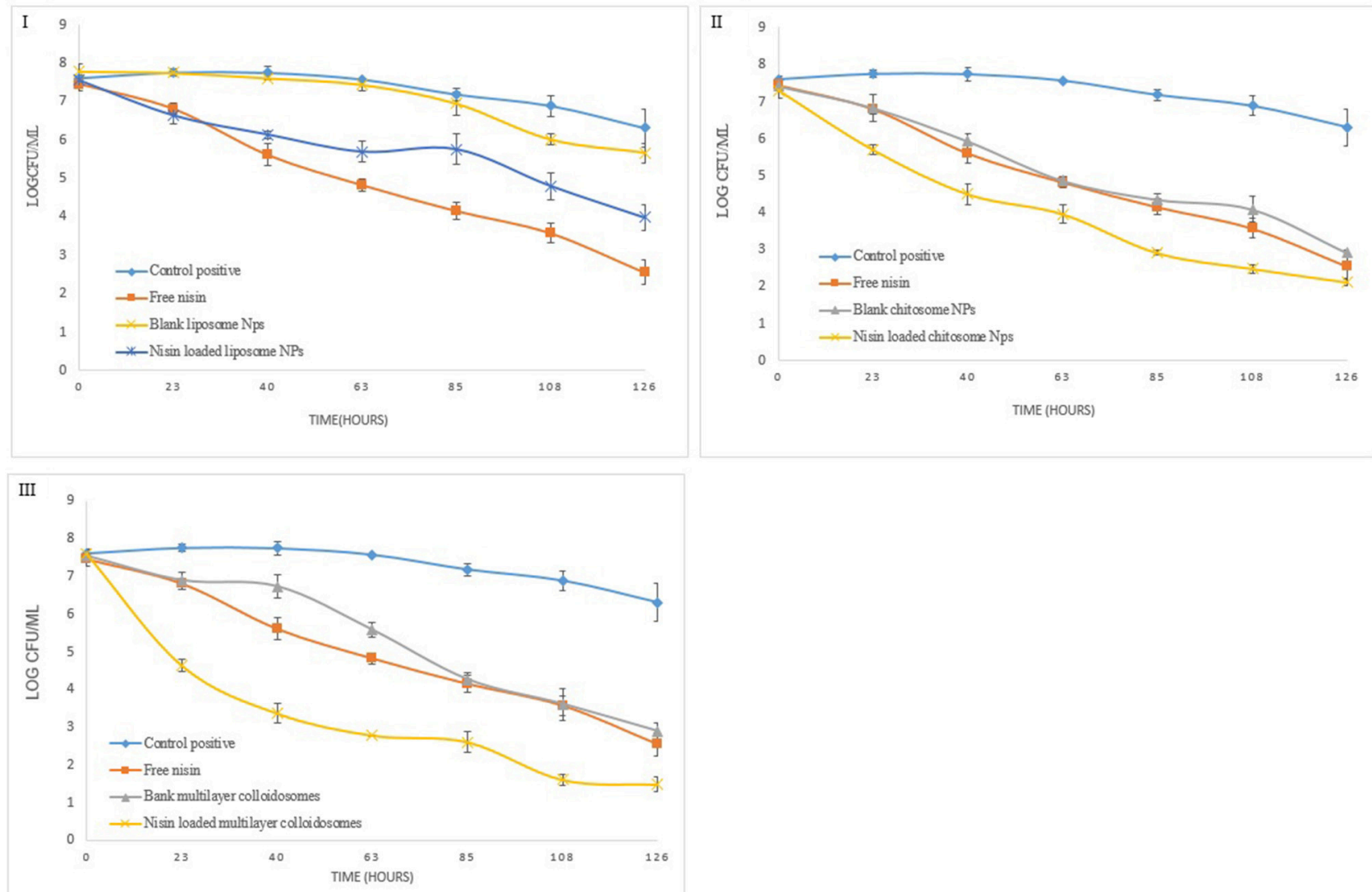

FIGURE 10 | Quantitative antibacterial analysis of free and encapsulated nisin in (I) liposome, (II) chitosome, and (III) multicomponent colloidal system against E. faecalis.
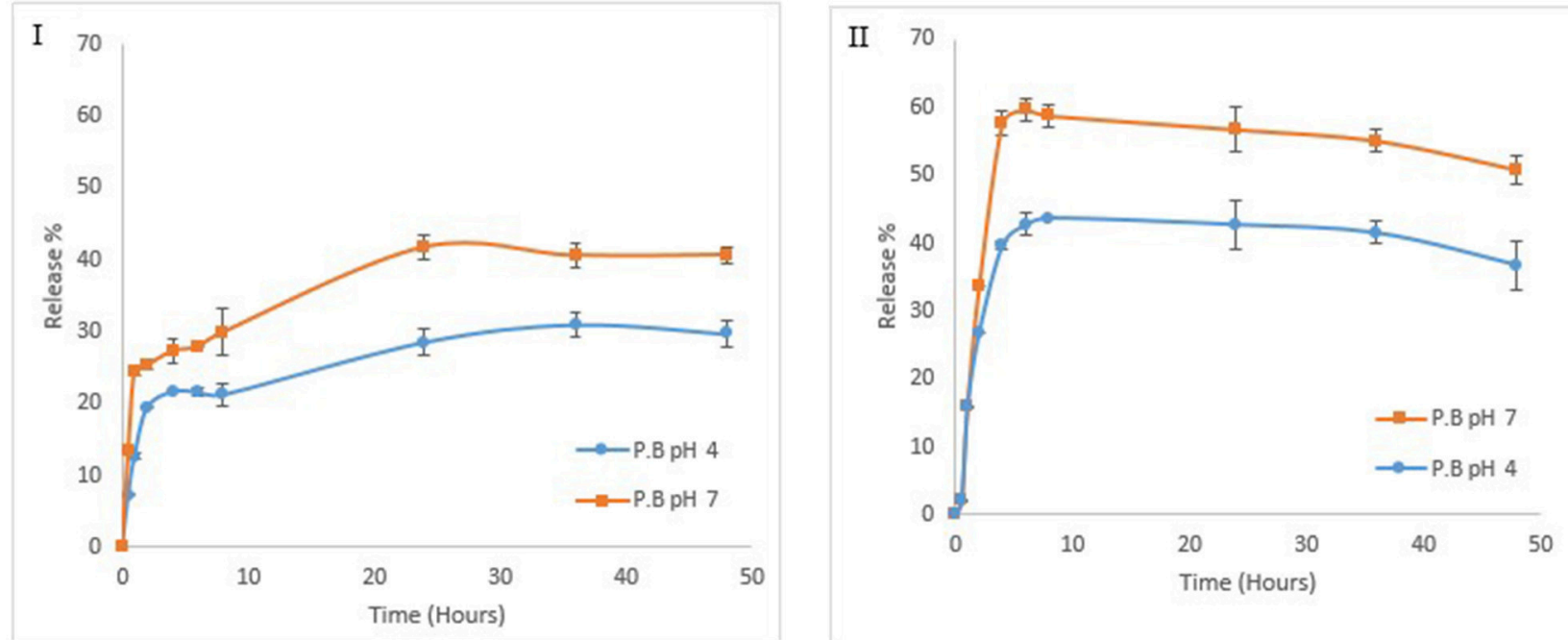

FIGURE 11 | Effect of different temperatures and pH on release kinetics of nisin from formulated NCS at $4^{\circ} \mathrm{C}$ (I) at $37^{\circ} \mathrm{C}$ (II)

Similarly, for Enterococcus faecalis, blank liposomes were not able to reduce bacterial count as shown in Figure 10. By using nisin loaded liposomes, $0.5 \log$ unit reduction in viable bacterial cell count was observed in first $24 \mathrm{~h}$ (8). Enterococcus count further reduced to only 2 to $2.5 \log$ units due to controlled release phenomenon. However, this reduction in bacterial count was less 
TABLE 3 | In Vitro release kinetics parameters of nisin from multicomponent collidosomes (MCCS).

\begin{tabular}{|c|c|c|c|c|}
\hline \multicolumn{2}{|c|}{ Nisin loaded MCCS } & \multirow{2}{*}{$\begin{array}{c}\text { Higuchi } \\
\text { Correlation } \\
\text { coefficient } r^{2}\end{array}$} & \multicolumn{2}{|c|}{ Korsmeyer-peppas } \\
\hline Temperature & $\mathrm{pH}$ & & $\begin{array}{l}\text { Correlation } \\
\text { coefficient } r^{2}\end{array}$ & $n$ \\
\hline \multirow[t]{2}{*}{$37^{\circ} \mathrm{C}$} & $\mathrm{pH} 4$ & 0.9557 & 0.9697 & $0.36 \pm 0.01$ \\
\hline & $\mathrm{pH} 7$ & 0.8632 & 0.9758 & $0.24 \pm 0.11$ \\
\hline \multirow[t]{2}{*}{$4^{\circ} \mathrm{C}$} & $\mathrm{pH} 4$ & 0.9226 & 0.9914 & $0.41 \pm 0.02$ \\
\hline & $\mathrm{pH} 7$ & 0.9147 & 0.9002 & $0.21 \pm 0.05$ \\
\hline
\end{tabular}

than free nisin. But for CTS coated liposomes, in first $24 \mathrm{~h}, 2$ $\log$ unit reduction in bacterial count was observed which further continued to a total of $5.2 \log$ unit decrease in 1 week.

Active multicomponent colloidosomes demonstrated best control over Enterococcus faecalis. Three log unit reduction was observed in $24 \mathrm{~h}$. E. faecalis enumeration was further reduced to a difference of 2-2.5 log units after $72 \mathrm{~h}$ for active multicomponent systems. Total $6.1 \mathrm{log}$ unit reduction in viable Enterococcus count was observed in 1 week.

Overall, we can conclude that the multicomponent colloidosomes exhibited an unmatched control against $L$. monocytogenes and E. faecalis. These resistant pathogens were not able to grow in the presence of multicomponent NCS due to two reasons, one by enhanced sustained release mechanism of nisin from multicomponent carriers (FernandezSaiz et al., 2010), and secondly alginate's gelling capacity reduced the bacterial growth by altering the oxygen and nutrients composition in the medium.

\section{In Vitro Controlled Release Kinetics of Nisin from Multicomponent NCS}

To check the controlled release of nisin in phosphate buffer saline (PBS), an in vitro experiment was conducted at $\mathrm{pH} 7$ and 4 on different temperatures e.g., physiological temperature $\left(37^{\circ} \mathrm{C}\right)$ and storage refrigerated temperature $\left(4^{\circ} \mathrm{C}\right)$. Sustained release of nisin from multicomponent NCS was monitored for $48 \mathrm{~h}$ (Figure 11). During initial hours, drug release rate increased gradually in similar manner at both temperatures and $\mathrm{pH}$, but afterwards observed drug release rate was higher at $37^{\circ} \mathrm{C}$ as compared to $4^{\circ} \mathrm{C}$ from multi-component colloidosomes. At $4^{\circ} \mathrm{C}$ nisin release was observed to be $41 \pm 1.6 \%$ in PBS at $\mathrm{pH} 7$ and $28 \pm 1.8 \%$ at $\mathrm{pH} 4$ after $24 \mathrm{~h}$. While at physiological temperature, $58 \pm 1.5 \%$ and $43 \pm 1 \%$ of the nisin released within $6 \mathrm{~h}$ at $\mathrm{pH} 7$ and $\mathrm{pH} 4$, respectively. Our observations indicated that there was a burst release during first $10 \mathrm{~h}$ at both $\mathrm{pH}$ values at $4^{\circ} \mathrm{C}$. However, the amount released was higher at $37^{\circ} \mathrm{C}$ for both $\mathrm{pH}$ values than $4^{\circ} \mathrm{C}$. Afterwards, the release rate was slow and steady in both $\mathrm{pH}$ conditions at different temperatures.

Whereas at $37^{\circ} \mathrm{C}$, rapid nisin release were observed in first $6 \mathrm{~h}$. Thus, a total of $59 \pm 1.7 \%$ and $43 \pm 3.6 \%$ of the nisin was released within $6 \mathrm{~h}$ at $\mathrm{pH} 7$ and $\mathrm{pH} 4$, respectively. After this point, gradual decrease in nisin release was observed at this temperature for both $\mathrm{pH}$ conditions. At low $\mathrm{pH}$ (slightly acidic $\mathrm{pH}$ ), positively charged CTS and tight network of ALG coating help in retaining the nisin and it is expected that this will also help in protecting the encapsulated nisin against the proteolytic degradation in the food systems. On the contrary, at $\mathrm{pH} 7$, relatively higher nisin release from multilayer colloidosomes could be realized due to the increased interaction between alkaline solvent and alginate shell. Moreover, high dissolution of alginate at this $\mathrm{pH}$ help in penetration of the solvent from alginate layer to chitosan layer in which nisin is present (Mukhopadhyay et al., 2015).

Furthermore, to investigate the mechanism of release kinetics (Fickian \& non Fickian diffusion), Higuchi and KorsmeyerPeppas mathematics models were applied to the data. Release profiles of nisin from MCCS were evaluated through regression coefficient $\left(r^{2}\right)$ and release exponent (n). As shown in Table 3, the $r^{2}$ values at $\mathrm{pH} 4$ for both temperatures $\left(37^{\circ} \mathrm{C}\right.$ and $\left.4^{\circ} \mathrm{C}\right)$ were close to 1 . However, regression coefficient at $\mathrm{pH} 7$ on $37^{\circ} \mathrm{C}$ by Higuchi model was considerably lower than 1 . This poor fitting data of nisin release at $\mathrm{pH} 7$ indicated the change in surface area of MCCS as a function of temperature. According to our study, controlled release data of nisin from MCCS was best fitted by Korsmeyer-Peppas model. Release exponent (n) value for release of nisin at both temperatures and $\mathrm{pH}$ were less than 0.45 . Therefore, Fickian diffusion is the controlling factor in nisin release from MCCS.

\section{In Vitro Hemolysis Assay}

In vivo cytotoxic behavior of multicomponent colloidosomes could be predicted by in vitro hemolysis assay. As a potential antimicrobial food preservative, MCCS may pass through epithelial membrane and come in contact with blood cells, therefore it is essential to analyze their hemolytic effect. Hence the prepared NLs and MCCS were tested for hemocompatibility (Figure 12A). All the nanoantimicrobials used in this study have shown negligible hemolysis relative to the value obtained for control positive (1\% SDS).

\section{In Vitro Cytotoxicity and Cell Viability Studies on HepG2 Cell Lines}

Cytotoxicity tests for different nano-formulations were performed on HepG2 cell lines (Figures 12BI-IV). The cytotoxicity of all the nano-formulations was negligible. For further cytotoxic analysis, SRB assay was performed to analyze the effect of MCCS on density of hepatic cells (Figure 12C). After $24 \mathrm{~h}$, hepatic cells monolayer was not affected by nisin loaded MCCS, and the cell density remained like the untreated control. These findings are in coherence with previous results reported for nontoxicity of chitosan based nano-antibiotics (Jamil et al., 2016a).

\section{CONCLUSION}

Carbohydrate polymers provide a useful platform to improve stability, entrapment, and controlled release of a wide variety of active agents. This study examined the influence of sodium alginate and CTS polymers' coating 

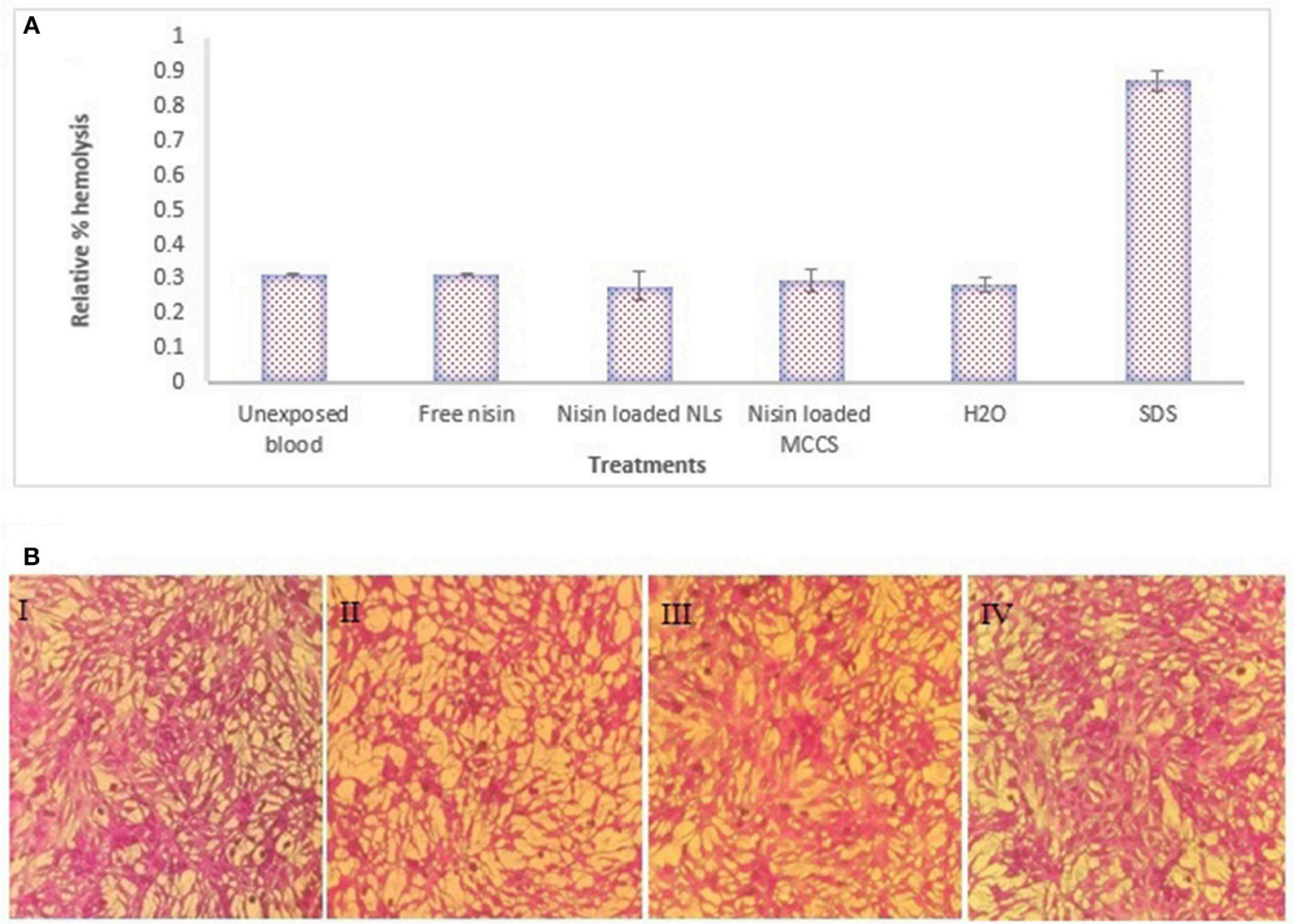

C

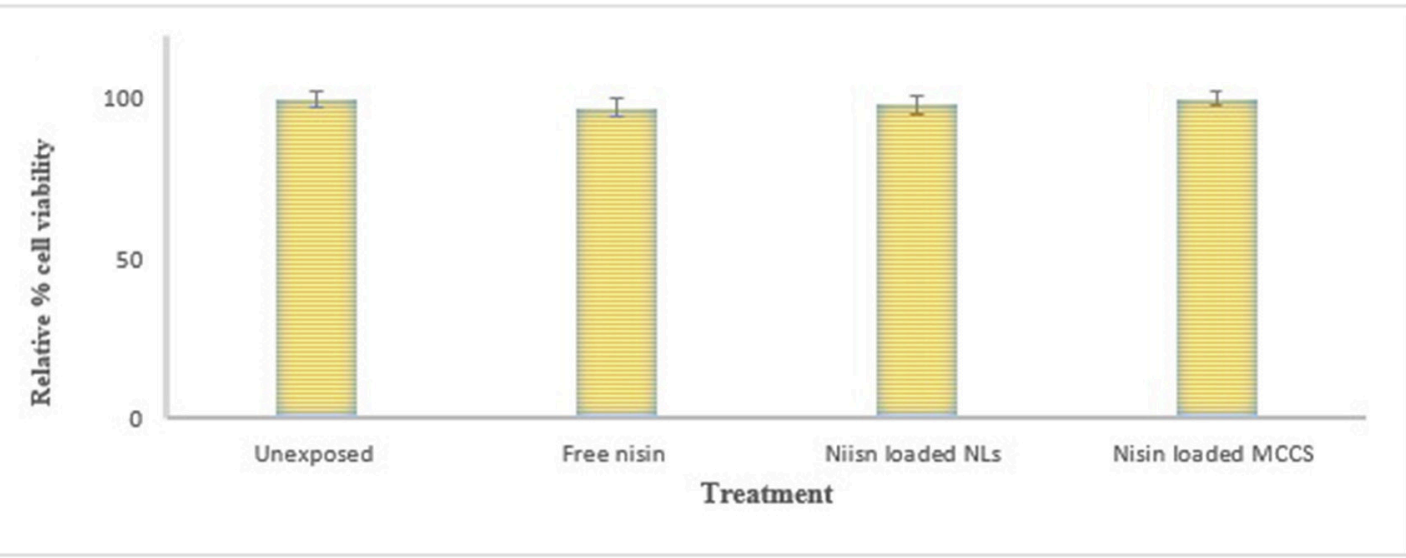

FIGURE 12 | Cytotoxicity analysis of nano formulations. (A) In vitro hemolysis assay on human blood cells. Evaluation of different formulation e.g., nisin, nisin loaded NLs and nisin loaded MCCS for relative \% hemolysis, (B) Cytotoxicity analysis on HepG2 liver cells treated with (I) untreated HepG2 cells (II) nisin (III) nisin loaded liposomes (IV) nisin loaded multicomponent colloidal system, (C) Relative \% cell viability of different nano-formulations against HepG2 determined by using SRB; following treatment with free nisin, nisin loaded liposomes and nisin loaded MCCS. All assay values were taken in triplicate and mean values \pm SD were calculated.

on the stability of liposomes. Physical properties of the fabricated multicomponent NCS revealed that these multilayer systems have high encapsulation efficiency than uncoated liposomes. Adding multiple layers and cross-linking of polymers on nano-liposome also improved their thermal stability without affecting their morphology. Multicomponent systems provided sustained release of antimicrobial agent (nisin) over longer period by Fickian diffusion, while being hemocompatible and nontoxic to human cells. Thus, due to enhanced controlled release and stability of nisin, these multicomponent colloidosomes could be useful for incorporating antimicrobial agents into functional foods e.g., dairy products and beverages to combat multidrug resistant pathogens in food products. 


\section{AUTHOR CONTRIBUTIONS}

TasN carried out all of the research work, compiled data and wrote the manuscript. SS performed TGA and DSC analyses and TayN helped in FTIR based studies of interaction between drug and polymer. RA performed the cytotoxicity assays. ZR carried out the zeta-sizer analyses. MI provided scientific and technical assistance in experimentation and compilation of data and manuscript write up.

\section{FUNDING}

This work was supported by the Higher Education Commission, Pakistan [NRPU grant No. 20-4260/R\&D/HEC/14/127].

\section{REFERENCES}

Adamczak, M. I., Martinsen, Ø. G., Smistad, G., and Hiorth, M. (2017). Polymer coated mucoadhesive liposomes intended for the management of xerostomia. Int. J. Pharm. 527, 72-78. doi: 10.1016/j.ijpharm.2017.05.032

Alavi, M., Karimi, N., and Safaei, M. (2017). Application of various types of liposomes in drug delivery systems. Adv. Pharm. Bull. 7:3. doi: 10.15171/apb.2017.002

Alishahi, A. (2014). Antibacterial effect of chitosan nanoparticle loaded with nisin for the prolonged effect. J. Food Saf. 34, 111-118. doi: 10.1111/jfs.12103

Almalik, A., Alradwan, I., Kalam, M. A., and Alshamsan, A. (2017). Effect of cryoprotection on particle size stability and preservation of chitosan nanoparticles with and without hyaluronate or alginate coating. Saudi Pharm. J. 25, 861-867 doi: 10.1016/j.jsps.2016.12.008

Aspridou, Z., Moschakis, T., Biliaderis, C. G., and Koutsoumanis, K. P. (2014). Effect of the substrate's microstructure on the growth of Listeria monocytogenes. Food Res. Int. 64, 683-691. doi: 10.1016/j.foodres.2014.07.031

Balay, D. R., Dangeti, R. V., Kaur, K., and McMullen, L. M. (2017). Purification of leucocin A for use on wieners to inhibit Listeria monocytogenes in the presence of spoilage organisms. Int. J. Food Microbiol. 255, 25-31. doi: 10.1016/j.ijfoodmicro.2017.05.016

Benmansour, N., Benmansour, A., Hanbali, F. E., González-Mas, M. C., Blázquez, M. A., Hakmaoui, A. E., et al. (2016). Antimicrobial activity of essential oil of Artemisia judaica L. from Algeria against multi-drug resistant bacteria from clinical origin. Flavour Fragrance J. 31, 137-142. doi: 10.1002/ffj.3291

Bhattarai, R., Sutradhar, T., Roy, B., Guha, P., Chettri, P., Mandal, A. K., et al. (2016). Double-tailed cystine derivatives as novel substitutes of phospholipids with special reference to liposomes. J. Phys. Chem. B. 120, 10744-10756. doi: 10.1021/acs.jpcb.6b06413

Caddeo, C., Díez-Sales, O., Pons, R., Carbone, C., Ennas, G., Puglisi, G., et al. (2016). Cross-linked chitosan/liposome hybrid system for the intestinal delivery of quercetin. J. Colloid Inter. Sci. 461, 69-78. doi: 10.1016/j.jcis.2015.09.013

Caetano, L. A., Almeida, A. J., and Gonçalves, L. (2016). Effect of experimental parameters on alginate/chitosan microparticles for BCG encapsulation. Mar. Drugs 14:90. doi: 10.3390/md14050090

Chandrasekar, V., Coupland, J. N., and Anantheswaran, R. C. (2017). Characterization of nisin containing chitosan-alginate microparticles. Food Hydrocoll. 69, 301-307. doi: 10.1016/j.foodhyd.2017.02.011

Cheng, L., Bulmer, C., and Margaritis, A. (2015). Characterization of novel composite alginate chitosan-carrageenan nanoparticles for encapsulation of BSA as a model drug delivery system. Curr. Drug Deliv. 12, 351-357. doi: 10.2174/1567201812666150114155948

Dai, F., Yan, W.-J., Du, Y.-T., Bao, X.-Z., Li, X.-Z., and Zhou, B. (2017). Structural basis, chemical driving forces and biological implications of flavones as $\mathrm{Cu}(\mathrm{II})$ ionophores. Free Rad. Biol. Med. 108, 554-563. doi: 10.1016/j.freeradbiomed.2017.04.023

de Oliveira Pedro, R., Goycoolea, F. M., Pereira, S., Schmitt, C. C., and Neumann, M. G. (2018). Synergistic effect of quercetin and $\mathrm{pH}$-responsive DEAE-chitosan carriers as drug delivery system for breast cancer treatment. Int. J. Biol. Macromol. 106, 579-586. doi: 10.1016/j.ijbiomac.2017.08.056

Draget, K. I., Moe, S. T., Skjak-Bræk, G., and Smidsrød, O. (2016). "9 Alginates," in Food Polysaccharides and their Applications, eds A. M. Stephen and G. O. Philips (Boca Raton, FL: CRC Press; Taylor and Francis Group), 160:289.

El-Houssiny, A., Ward, A., Mostafa, D., Abd-El-Messieh, S., Abdel-Nour, K., Darwish, M., et al. (2016). Drug-polymer interaction between glucosamine sulfate and alginate nanoparticles: FTIR, DSC and dielectric

spectroscopy studies. Adv. Nat. Sci. Nanosci. Nanotechnol. 7:025014. doi: 10.1088/2043-6262/7/2/025014

Emami, S., Azadmard-Damirchi, S., Peighambardoust, S. H., Valizadeh, H., and Hesari, J. (2016). Liposomes as carrier vehicles for functional compounds in food sector. J. Exp. Nanosci. 11, 737-759. doi: 10.1080/17458080.2016.1148273

Fernandez-Saiz, P., Soler, C., Lagaron, J. M., and Ocio, M. J. (2010). Effects of chitosan films on the growth of Listeria monocytogenes, Staphylococcus aureus and Salmonella spp. in laboratory media and in fish soup. Int. J. Food Microbiol. 137, 287-294. doi: 10.1016/j.ijfoodmicro.2009.11.016

Fu, Y., Sarkar, P., Bhunia, A. K., and Yao, Y. (2016). Delivery systems of antimicrobial compounds to food. Trends Food Sci. Technol. 57(Pt A), 165-177. doi: $10.1016 /$ j.tifs.2016.09.013

Furuya, D. C., Costa, S. A. D., Oliveira, R. C. D., Ferraz, H. G., Pessoa Junior, A., and Costa, S. M. D. (2017). Fibers obtained from alginate, chitosan and hybrid used in the development of scaffolds. Mater. Res. 20, 377-386 doi: 10.1590/1980-5373-mr-2016-0509

Gandomi, H., Abbaszadeh, S., Misaghi, A., Bokaie, S., and Noori, N. (2016). Effect of chitosan-alginate encapsulation with inulin on survival of Lactobacillus rhamnosus GG during apple juice storage and under simulated gastrointestinal conditions. LWT Food Sci. Technol. 69, 365-371. doi: 10.1016/j.lwt.2016.01.064

George, M., and Abraham, T. E. (2006). Polyionic hydrocolloids for the intestinal delivery of protein drugs: alginate and chitosan - a review. J. Control. Release. 114, 1-14. doi: 10.1016/j.jconrel.2006.04.017

Gharsallaoui, A., Oulahal, N., Joly, C., and Degraeve, P. (2016). Nisin as a food preservative: part 1: physicochemical properties, antimicrobial activity, and main uses. Crit. Rev. Food Sci. Nutr. 56, 1262-1274. doi: $10.1080 / 10408398.2013 .763765$

Greninger, A. L., Chatterjee, S. S., Chan, L. C., Hamilton, S. M., Chambers, H. F., and Chiu, C. Y. (2016). Whole-genome sequencing of methicillinresistant Staphylococcus aureus resistant to fifth-generation cephalosporins reveals potential non-mecA mechanisms of resistance. PLoS ONE 11:e0149541. doi: 10.1371/journal.pone.0149541

Han, D., Sherman, S., Filocamo, S., and Steckl, A. J. (2017). Long-term antimicrobial effect of nisin released from electrospun triaxial fiber membranes. Acta Biomater. 53, 242-249. doi: 10.1016/j.actbio.2017.02.029

Hervault, A., Dunn, A. E., Lim, M., Boyer, C., Mott, D., Maenosono, S. et al. (2016). Doxorubicin loaded dual $\mathrm{pH}$-and thermo-responsive magnetic nanocarrier for combined magnetic hyperthermia and targeted controlled drug delivery applications. Nanoscale 8, 12152-12161. doi: 10.1039/C5NR0 $7773 \mathrm{G}$

$\mathrm{Hu}, \mathrm{Y} ., \mathrm{Wu}, \mathrm{T} ., \mathrm{Wu}, \mathrm{C} ., \mathrm{Fu}, \mathrm{S} ., \mathrm{Yuan}, \mathrm{C}$. , and Chen, S. (2017). Formation and optimization of chitosan-nisin microcapsules and its characterization for antibacterial activity. Food Control 72(Pt A), 43-52. doi: 10.1016/j.foodcont.2016.06.013

Imran, M., Revol-Junelles, A.-M., Paris, C., Guedon, E., Linder, M., and Desobry, S. (2015). Liposomal nanodelivery systems using soy and marine lecithin to encapsulate food biopreservative nisin. LWT Food Sci. Technol. 62, 341-349. doi: 10.1016/j.lwt.2014.12.046

Jain, A., and Jain, S. K. (2016). In vitro release kinetics model fitting of liposomes: an insight. Chem. Phys. Lipids 201, 28-40. doi: 10.1016/j.chemphyslip.2016.10.005

Jamil, B., Abbasi, R., Abbasi, S., Imran, M., Khan, S. U., Ihsan, A., et al. (2016a). Encapsulation of cardamom essential oil in chitosan nano-composites: in-vitro efficacy on antibiotic-resistant bacterial pathogens and cytotoxicity studies. Front. Microbiol. 7:1580. doi: 10.3389/fmicb.2016.01580

Jamil, B., Habib, H., Abbasi, S., Nasir, H., Rahman, A., Rehman, A. et al. (2016b). Cefazolin loaded chitosan nanoparticles to cure multi 
drug resistant Gram-negative pathogens. Carbohydr. Polym. 136, 682-691. doi: 10.1016/j.carbpol.2015.09.078

Jorge, P., Pérez-Pérez, M., Pérez Rodríguez, G., Pereira, M. O., and Lourenço, A. (2017). A network perspective on antimicrobial peptide combination therapies: the potential of colistin, polymyxin B and nisin. Int. J. Antimicrob. Agents 49, 668-676. doi: 10.1016/j.ijantimicag.2017.02.012

Khalil, H. A., Saurabh, C. K., Tye, Y., Lai, T., Easa, A., Rosamah, E., et al. (2017). Seaweed based sustainable films and composites for food and pharmaceutical applications: a review. Renewable Sustainable Energy Rev. 77, 353-362. doi: $10.1016 /$ j.rser.2017.04.025

Khan, I., and Oh, D.-H. (2016). Integration of nisin into nanoparticles for application in foods. Innovat. Food Sci. Emerg. Technol. 34, 376-384. doi: 10.1016/j.ifset.2015.12.013

Koirala, S., Roy, B., Guha, P., Bhattarai, R., Sapkota, M., Nahak, P., et al. (2016). Effect of double tailed cationic surfactants on the physicochemical behavior of hybrid vesicles. RSC Adv. 6, 13786-13796. doi: 10.1039/C5RA1 $7774 \mathrm{~J}$

Krivorotova, T., Cirkovas, A., Maciulyte, S., Staneviciene, R., Budriene, S., Serviene, E., et al. (2016). Nisin-loaded pectin nanoparticles for food preservation. Food Hydrocoll. 54, 49-56. doi: 10.1016/j.foodhyd.2015.09.015

Li, J., Jiang, C., Lang, X., Kong, M., Cheng, X., Liu, Y., et al. (2016). Multilayer sodium alginate beads with porous core containing chitosan based nanoparticles for oral delivery of anticancer drug. Int. J. Biol. Macromol. 85, 1-8. doi: 10.1016/j.ijbiomac.2015.12.064

Li, X., Qi, J., Xie, Y., Zhang, X., Hu, S., Xu, Y., et al. (2013). Nanoemulsions coated with alginate/chitosan as oral insulin delivery systems: preparation, characterization, and hypoglycemic effect in rats. Int. J. Nanomed. 8, 23-32. doi: $10.2147 / \mathrm{IJN}$.S38507

Liu, W., Kong, Y., Tu, P., Lu, J., Liu, C., Liu, W., et al. (2017). Physical-chemical stability and in vitro digestibility of hybrid nanoparticles based on the layer-bylayer assembly of lactoferrin and BSA on liposomes. Food Funct. 8, 1688-1697. doi: $10.1039 / \mathrm{C} 7 \mathrm{FO} 00308 \mathrm{~K}$

Liu, W., Liu, W., Ye, A., Peng, S., Wei, F., Liu, C., et al. (2016). Environmental stress stability of microencapsules based on liposomes decorated with chitosan and sodium alginate. Food Chem. 196, 396-404. doi: 10.1016/j.foodchem.2015.09.050

Lopes, M., Abrahim, B., Veiga, F., Seiça, R., Cabral, L. M., Arnaud, P., et al. (2016). Preparation methods and applications behind alginate-based particles. Expert Opin. Drug Deliv. 14, 769-782. doi: 10.1080/17425247.2016.1214564

Lopes, N. A., and Brandelli, A. (2017). Nanostructures for delivery of natural antimicrobials in food. Crit. Rev. Food Sci. Nutr. 10, 1-11. doi: 10.1080/10408398.2017.1308915

Manatunga, D. C., de Silva, R. M., de Silva, K. M. N., de Silva, N., Bhandari, S., Yap, Y. K., et al. (2017). pH responsive controlled release of anticancer hydrophobic drugs from sodium alginate and hydroxyapatite bicoated iron oxide nanoparticles. Eur. J. Pharm. Biopharm. 117, 29-38. doi: 10.1016/j.ejpb.2017.03.014

Miller, W. R., Murray, B. E., Rice, L. B., and Arias, C. A. (2016). Vancomycinresistant enterococci: therapeutic challenges in the 21 st century. Infect. Dis. Clin. North Am. 30, 415-439. doi: 10.1016/j.idc.2016.02.006

Mukhopadhyay, P., Chakraborty, S., Bhattacharya, S., Mishra, R., and Kundu, P. (2015). pH-sensitive chitosan/alginate core-shell nanoparticles for efficient and safe oral insulin delivery. Int. J. Biol. Macromol. 72, 640-648. doi: 10.1016/j.ijbiomac.2014.08.040

Mukhopadhyay, P., Maity, S., Chakraborty, S., Rudra, R., Ghodadara, H., Solanki, M., et al. (2016). Oral delivery of quercetin to diabetic animals using novel $\mathrm{pH}$ responsive carboxypropionylated chitosan/alginate microparticles. RSC Adv. 6, 73210-73221. doi: 10.1039/C6RA12491G
Nguyen, T. X., Huang, L., Gauthier, M., Yang, G., and Wang, Q. (2016). Recent advances in liposome surface modification for oral drug delivery. Nanomedicine 11, 1169-1185. doi: $10.2217 / \mathrm{nnm} .16 .9$

Niaz, T., Shabbir, S., Manzoor, S., Rehman, A., Rahman, A., Nasir, H., et al. (2016). Antihypertensive nano-ceuticales based on chitosan biopolymer: Physicochemical evaluation and release kinetics. Carbohydr. Polym. 142, 268-274. doi: 10.1016/j.carbpol.2016.01.047

Pandey, S., and Ramontja, J. (2016). Sodium alginate stabilized silver nanoparticles-silica nanohybrid and their antibacterial characteristics. Int. J. Biol. Macromol. 93(Pt A), 712-723. doi: 10.1016/j.ijbiomac.2016.09.033

Paques, J. P., van der Linden, E., van Rijn, C. J., and Sagis, L. M. (2014), Preparation methods of alginate nanoparticles. Adv. Colloid Inter. Sci. 209, 163-171. doi: 10.1016/j.cis.2014.03.009

Peng, S., Zou, L., Liu, W., Li, Z., Liu, W., Hu, X., et al. (2017). Hybrid liposomes composed of amphiphilic chitosan and phospholipid: preparation, stability and bioavailability as a carrier for curcumin. Carbohydr. Polym. 156, 322-332. doi: 10.1016/j.carbpol.2016.09.060

Pistone, S., Rykke, M., Smistad, G., and Hiorth, M. (2017). Polysaccharide-coated liposomal formulations for dental targeting. Int. J. Pharm. 516, 106-115. doi: 10.1016/j.ijpharm.2016.11.028

Raval, R., Rangnekar, R. H., and Raval, K. (2017). "Optimization of chitosan nanoparticles synthesis and its applications in fatty acid absorption," in Materials, Energy and Environment Engineering, eds B. Mohan, G. Raj Srinikethan, and B. C. Meikap (Singapore: Springer), 253-256.

Sadiq, S., Imran, M., Habib, H., Shabbir, S., Ihsan, A., Zafar, Y., et al. (2016). Potential of monolaurin based food-grade nano-micelles loaded with nisin $\mathrm{Z}$ for synergistic antimicrobial action against Staphylococcus aureus. LWT Food Sci. Technol. 71, 227-233. doi: 10.1016/j.lwt.2016.03.045

Seeli, D. S., Dhivya, S., Selvamurugan, N., and Prabaharan, M. (2016). Guar gum succinate-sodium alginate beads as a $\mathrm{pH}$-sensitive carrier for colon-specific drug delivery. Int. J. Biol. Macromol. 91, 45-50. doi: 10.1016/j.ijbiomac.2016.05.057

Sood, A., Arora, V., Shah, J., Kotnala, R. K., and Jain, T. K. (2017). Multifunctional gold coated iron oxide core-shell nanoparticles stabilized using thiolated sodium alginate for biomedical applications. Mater. Sci. Engineer. C. 80, 274-281. doi: 10.1016/j.msec.2017.05.079

Szekalska, M., Puciłowska, A., Szymanska, E., Ciosek, P., and Winnicka, K. (2016). Alginate: current use and future perspectives in pharmaceutical and biomedical applications. Int. J. Polym. Sci. 2016:7697031. doi: 10.1155/2016/7697031

Tan, C., Feng, B., Zhang, X., Xia, W., and Xia, S. (2016). Biopolymercoated liposomes by electrostatic adsorption of chitosan (chitosomes) as novel delivery systems for carotenoids. Food Hydrocoll. 52, 774-784. doi: 10.1016/j.foodhyd.2015.08.016

Tavernier, I., Wijaya, W., Van der Meeren, P., Dewettinck, K., and Patel, A. R. (2016). Food-grade particles for emulsion stabilization. Trends Food Sci. Technol. 50, 159-174. doi: 10.1016/j.tifs.2016.01.023

Conflict of Interest Statement: The authors declare that the research was conducted in the absence of any commercial or financial relationships that could be construed as a potential conflict of interest.

Copyright (๔ 2018 Niaz, Shabbir, Noor, Abbasi, Raza and Imran. This is an openaccess article distributed under the terms of the Creative Commons Attribution License (CC BY). The use, distribution or reproduction in other forums is permitted, provided the original author(s) or licensor are credited and that the original publication in this journal is cited, in accordance with accepted academic practice. No use, distribution or reproduction is permitted which does not comply with these terms. 